\section{La población en riesgo y la calidad del agua al sur de la Zona Metropolitana de Guadalajara (Jalisco, México)}

The population at risk and the quality of the water in the south of the Guadalajara Metropolitan Area (Jalisco, México)

\section{Enrique Castillo-Figueroa}

Universidad de Guadalajara

Guadalajara, México

enrisland@gmail.com

(iD) https://orcid.org/0000-0001-5154-070X

\section{RESUMEN}

El presente artículo muestra la problemática ambiental al sur de la Zona Metropolitana de Guadalajara, en el Estado de Jalisco, México. El objetivo es conocer las afectaciones ambientales en que se encuentran los habitantes de este territorio. Se realizó una revisión bibliográfica y hemerográfica de los distintos estudios de calidad de agua superficial, efectuados por parte de autoridades estatales, universidades y organizaciones no gubernamentales, enfocados al arroyo y presa El Ahogado. Además, se hizo una proyección socio espacial de los habitantes que están expuestos a los contaminantes en el agua superficial: bario, cromo, hierro, mercurio y zinc. El Estado ha tenido conocimiento de la degradación ambiental desde hace 40 años. Esto nos habla de una re-victimización del espacio socioambiental: la industria no ha sido sancionada, el crecimiento urbano es desordenado y las exigencias de la población en materia de salud no han sido atendidas.

PALABRAS CLAVE: Riesgo, Degradación ambiental, Metales pesados, Agua, Industria.

\section{ABSTRACT}

This article deals with the environmental issues south of the Guadalajara Metropolitan Area, in the State of Jalisco, Mexico. Its objective is to foster awareness of the environmental impact facing the inhabitants of this geographical area. A review of books, articles and official reports of the various surface water quality studies done by state authorities, universities and non-governmental organizations was carried out, focused on the El Ahogado creek and dam. In addition, we undertake a socio-spatial projection of the inhabitants which are exposed to contaminants found in surface water: barium, chromium, iron, mercury and zinc. The State has been aware of the environmental degradation for 40 years. This speaks to the re-victimization of the socioenvironmental space where the water industry has not been sanctioned, urban sprawl is unregulated and the demands of the population in terms of health have not been met.

KEYWORDS: Risk, Environmental degradation, Heavy metals, Water, Industry.

(C) Universidad de Jaén (España).

Seminario Permanente Agua, Territorio y Medio Ambiente (CSIC) 
População em risco e qualidade da água no

sul da Área Metropolitana de Guadalajara (Jalisco, México)

\section{SUMÁRIO}

Este artigo mostra os problemas ambientais no sul da Área Metropolitana de Guadalajara, no Estado de Jalisco, México. O objetivo é conhecer as afetações ambientais em que se encontram os habitantes deste território. Foi feita uma revisão bibliográfica e jornalística dos diferentes estudos de qualidade das águas superficiais realizados por autoridades estatais, universidades e organizações não governamentais, com foco no riacho e na barragem de El Ahogado. Além disso, foi feita uma projeção sócio-espacial dos habitantes que estão expostos a contaminantes na água superficial: bário, cromo, ferro, mercúrio e zinco. O Estado está consciente da degradação ambiental há 40 anos. Isto nos fala de uma revalorização do espaço socioambiental: a indústria não foi sancionada, o crescimento urbano é desordenado e as demandas de saúde da população não foram atendidas.

PALAVRAS-CHAVE: Risco, Degradação ambiental, Metais pesados,

Água, Indústria.

Population à risque et qualité de l'eau

dans le sud de la région métropolitaine de

Guadalajara (Jalisco, Mexique)

\section{RÉSUMÉ}

Cet article montre les problèmes environnementaux dans le sud de la zone métropolitaine de Guadalajara, dans l'État de Jalisco, au Mexique. L'objectif est de connaître les affections environnementales dans lesquelles se trouvent les habitants de ce territoire. Une revue bibliographique et journalistique a été faite des différentes études sur la qualité des eaux de surface réalisées par les autorités de l'État, les universités et les organisations non gouvernementales, en se concentrant sur le ruisseau et le barrage d'El Ahogado. En outre, une projection socio-spatiale a été réalisée sur les habitants qui sont exposés aux contaminants des eaux de surface : baryum, chrome, fer, mercure et zinc. L'État est conscient de la dégradation de l'environnement depuis 40 ans. Cela nous parle d'une re-victimisation de l'espace socio-environnemental : l'industrie n'a pas été sanctionnée, la croissance urbaine est désordonnée et les demandes de santé de la population n'ont pas été satisfaites.

MOTS-CLÉS: Risque, Dégradation de l'environnement, Métaux lourds, Eau, Industrie.
Popolazione a rischio e qualità dell'acqua nel sud dell'area metropolitana di Guadalajara (Jalisco, Messico)

\section{SOMMARIO}

Questo articolo mostra i problemi ambientali nel sud dell'area metropolitana di Guadalajara, nello Stato di Jalisco, Messico. L'obiettivo è quello di conoscere le affezioni ambientali in cui si trovano gli abitanti di questo territorio. È stata fatta una rassegna bibliografica e giornalistica dei diversi studi sulla qualità delle acque superficiali effettuati da autorità statali, università e organizzazioni non governative, con particolare attenzione al torrente e alla diga di El Ahogado. Inoltre, è stata effettuata una proiezione socio-spaziale degli abitanti esposti ai contaminanti presenti nelle acque superficiali: bario, cromo, ferro, mercurio e zinco. Lo Stato è consapevole del degrado ambientale da 40 anni. Questo ci parla di una rivittimizzazione dello spazio socioambientale: l'industria non è stata sanzionata, la crescita urbana è disordinata e le esigenze di salute della popolazione non sono state soddisfatte.

PAROLE CHIAVE: Rischio, Degrado ambientale, Metalli pesanti, Acqua, Industria. 


\section{Introducción}

Este artículo se deriva de un capítulo de nuestra tesis doctoral $^{1}$ realizada entre los años 2015-2019, en el que se analizaron diversos trabajos referentes a la calidad del agua al sur de la Zona Metropolitana de Guadalajara (ZMG), en el estado de Jalisco, México. El crecimiento de la ciudad se ha extendido hacia una zona industrial y esto ha puesto en evidencia la contaminación del agua superficial y los riesgos sanitarios.

Los tres niveles de gobierno en México -federal, estatal y municipal- han reconocido el deterioro ambiental de este territorio desde la década de 1980. No obstante, el gobierno federal no ha hecho lo suficiente para regular las descargas industriales (desde la modificación de las leyes ambientales a las sanciones a los infractores). En dicho espacio geográfico existen 2.848 empresas manufactureras, lo que constituye el $24 \%$ de la producción de la ZMG y el $14 \%$ de la entidad jalisciense.

Por otra parte, el gobierno estatal de Jalisco delimitó esta zona como Polígono de Fragilidad Ambiental (POFA), que abarca una parte de diez municipios: Guadalajara, Ixtlahuacán del Río, Juanacatlán, El Salto, Tlajomulco de Zúñiga, Tala, Tlaquepaque, Tonalá, Zapotlanejo y Zapopan. Entre las medidas adoptadas para reducir la contaminación del agua está la instalación de una Planta de Tratamiento de Aguas Residuales (PTAR). Sin embargo, solo trata las provenientes del sector doméstico y no las que se generan en la actividad industrial.

El gobierno municipal, como última unidad político-administrativa del Estado mexicano, ha permitido la construcción de viviendas de interés social en un espacio degradado ambientalmente. Además, existe una declaratoria de veda en la extracción de los acuíferos subterráneos. La carencia de agua potable y otros servicios básicos en estos nuevos asentamientos humanos ha llevado a la manifestación pública. Asimismo, se han gestado organizaciones sociales que han denunciado por más de dos décadas las muertes y enfermedades relacionadas con la contaminación del río Santiago y el arroyo El Ahogado.

\section{Algunos casos de crisis ambiental en el mundo}

Los impactos ambientales de carácter local son parte de una crisis ambiental más amplia. El caso de la ampliación

\footnotetext{
1. Castillo, 2019
}

del Canal de Panamá nos demuestra una desigualdad social. Por el mismo transitan entre 13.000 y 14.000 buques cada año. En 2005, se generaron 1.500 millones de dólares, de estos un tercio fueron entregados al gobierno panameño. No obstante, más del $40 \%$ de la población panameña es pobre, de estos el $26,5 \%$ viven en pobreza extrema. Esas desigualdades han favorecido a las elites de poder en el discurso social y en la defensa de sus intereses a través del supuesto interés general o beneficio social extendido ${ }^{2}$. Otro de los casos es el de la Cuenca Matanza Riachuelo ${ }^{3}$ en Argentina. La crisis ambiental tiene su origen en la omisión del manejo de los recursos naturales y las actividades agroindustriales desde el siglo XIX. A lo largo del tiempo, la producción y exportación de productos agrícolas generó saladeros, curtiembres, frigoríficos y otras industrias que van desde los astilleros hasta la creación de un polo petroquímico. Durante varias décadas las industrias no le dieron tratamiento a sus aguas residuales, que eran vertidas a la cuenca. Esto provocó afectaciones en la población, tanto de enfermedades respiratorias como de la piel (la población infantil era la más afectada). En el año 2004 se inició una demanda en contra del Estado, de empresas nacionales, provinciales y municipales, públicas y privadas ${ }^{4}$. El juez se esforzó en resarcir los daños ambientales; exigiendo a la presentación de informes, estipulando plazos e, incluso, imponiendo multas a los responsables del retraso de las obras acordadas ${ }^{5}$.

La crisis ambiental expresa el dominio hegemónico de la organización del mundo moderno. La cuestión ambiental es un tema que busca la reconstitución de las ciencias sociales y una refundamentación de los modos de habitar el mundo. Más que una sociología de la interculturalidad llama a reformar la vida humana y edificar una sociología de la otredad, de la racionalidad ambiental en la construcción de otros mundos posibles ${ }^{6}$.

La imagen de la crisis ambiental como un agregado de problemas interrelacionados a nivel mundial sirve para deslindar responsabilidades por etapa generacio-

\footnotetext{
2. Aledo, 2006.

3. Comprende parte de la ciudad de Buenos Aires y los municipios de Almirante Brown, Avellaneda, Cañuelas, Esteban Echeverría, General Las Heras, La Matanza, Lanús, Lomas de Zamora, Marcos Paz, Merlo y San Vicente.

4. "La demanda fue interpuesta el 14 de julio de 2004 ante la Corte Suprema de Justicia de la Nación. [...]El grupo de los demandantes se componía de: Vecinos de la Cuenca Matanza-Riachuelo (CMR), especialmente de la denominada 'Villa Inflamable', ubicada en Dock Sud, Partido de Avellaneda, Provincia de Buenos Aires; y Profesionales (médicos, psicólogos, odontólogos y enfermeros) del Hospital Interzonal de Agudos Pedro Fiorito de la ciudad de Avellaneda, Provincia de Buenos Aires". Cousido, 2010, 9.

5. Cousido, 2010.

6. Leff, 2014, 15, 33 y 41.
} 
nal de distintas sociedades humanas ${ }^{7}$. En ese contexto global, no solo interesa analizar o criticar los alcances del crecimiento económico, sino la construcción de nuevas prácticas que garanticen un mundo sustentable, el cuidado de la naturaleza y el respeto a los derechos humanos.

Las situaciones de peligro no pueden mentir en las nuevas desigualdades sociales a escala global. Surgen en situaciones de clase y las situaciones de riesgo se disfrazan: "el proletariado de la sociedad mundial del riesgo vive bajo las chimeneas, junto a las refinerías y fábricas químicas en los centros industriales del Tercer Mundo [...] hay una fuerza de atracción sistemática entre la pobreza extrema y los riesgos extremos" ${ }^{\text {. }}$. De igual forma, existen poblaciones urbanas, rurales y pueblos originarios, que son víctimas de los efectos de la crisis ambiental, propiciada por las actividades industriales en los países en "vías de desarrollo".

\section{Estructuración del artículo}

El trabajo se divide en tres apartados. El primero de ellos tiene que ver con la revisión de las investigaciones realizadas por parte de las autoridades gubernamentales, asociaciones civiles y académicos en referencia a la calidad del agua en la presa El Ahogado, afluente que recibe las aguas residuales del sur de la ZMG, reconocida como POFA. Asimismo, se explican los efectos que producen los metales pesados presentes en los cuerpos de agua y los riesgos sanitarios por la exposición a estos. Y el último nos describe el tipo de empresas que se encuentran instaladas en este territorio.

\section{Metodología}

Se realizó una revisión bibliográfica y hemerográfica de los distintos estudios de calidad del agua, enfocados en el arroyo y en la presa El Ahogado. En total se examinaron siete investigaciones. La primera de ellas data de 1980 y la última es de 2017. Ello nos habla de un periodo cercano a los cuarenta años, en el que se ha documentado la degradación ambiental de estos cuerpos de agua. El análisis de esos trabajos nos llevó a realizar diversas representaciones gráficas ${ }^{9} \mathrm{de}$

\footnotetext{
7. Meira Cartea, 2006, 115.

8. Beck, 1986, 47.

9. Se realizaron un total de nueve mapas con la ayuda del programa Arcgis 10.3.
}

lo que acontece en este territorio: desde la delimitación del POFA (decretada por el gobierno de Jalisco en 2010), los puntos de muestreo de calidad de agua superficial, la ubicación de las presas, la actividad industrial y la zona de riesgo ambiental. Se valoró a una distancia de cinco kilómetros del afluente en cuestión, con base en un estudio realizado en el río Kymijoki, al sur de Finlandia ${ }^{10}$. En ese afluente se encontró dibenzodioxinas policloradas y dibenzofuranos ${ }^{11}$, determinándose que para su población existían estimaciones de riesgo elevadas a $<1 \mathrm{~km}$ y ligeramente elevadas a $<5 \mathrm{~km}$.

\section{Objetivo}

El interés de nuestra investigación fue conocer las condiciones ambientales en que se encontraba la población de esta zona con el afán de estimar el riesgo sanitario, relacionado con los contaminantes presentes en el agua superficial ${ }^{12}$.

\section{El panorama ambiental al sur de la Zona Metropolitana de Guadalajara}

El crecimiento urbano de la ZMG se ha dado de una manera desordenada en los últimos 20 años. Esta expansión es paralela a la actividad industrial, que lleva más de cuarenta años instalada en la zona. La expansión urbana e industrial se ha realizado hacia el sur de la metrópoli, en lo que hoy se conoce como el POFA. En el territorio residen 1.411 .099 personas, que representan el $32 \%$ de la población total de la ZMG de acuerdo con el Instituto Nacional de Estadística y Geografía (INEGI) (Mapa 1).

Esta demarcación ${ }^{13}$ (en color rojo, como se aprecia en el Mapa 1) conformada por la fracción de diez municipios $^{14}$, ha sido reconocida por el propio gobierno del estado de Jalisco, como POFA. La autoridad ha propuesto una serie de medidas para contrarrestar la degradación ambiental en esta delimitación desde el año 2010.

\footnotetext{
10. Verkasalo et al., 2004

11. A pesar de que son sustancias diferentes a las encontradas en nuestro objeto de estudio, este trabajo nos sirve para delimitar nuestra zona de riesgo.

12. De acuerdo con la OMS (2020), la falta de agua potable y de un saneamiento de aguas residuales, sumado a una higiene deficiente, provoca 842.000 muertes al año en países de bajos ingresos.

13. Tiene una superficie de $745,22 \mathrm{~km}^{2}$.

14. Guadalajara, Ixtlahuacán del Río, Juanacatlán, El Salto, Tlajomulco de Zúñiga, Tala, Tlaquepaque, Tonalá, Zapotlanejo y Zapopan.
} 
Mapa 1. Ubicación geográfica del POFA y crecimiento de la ZMG
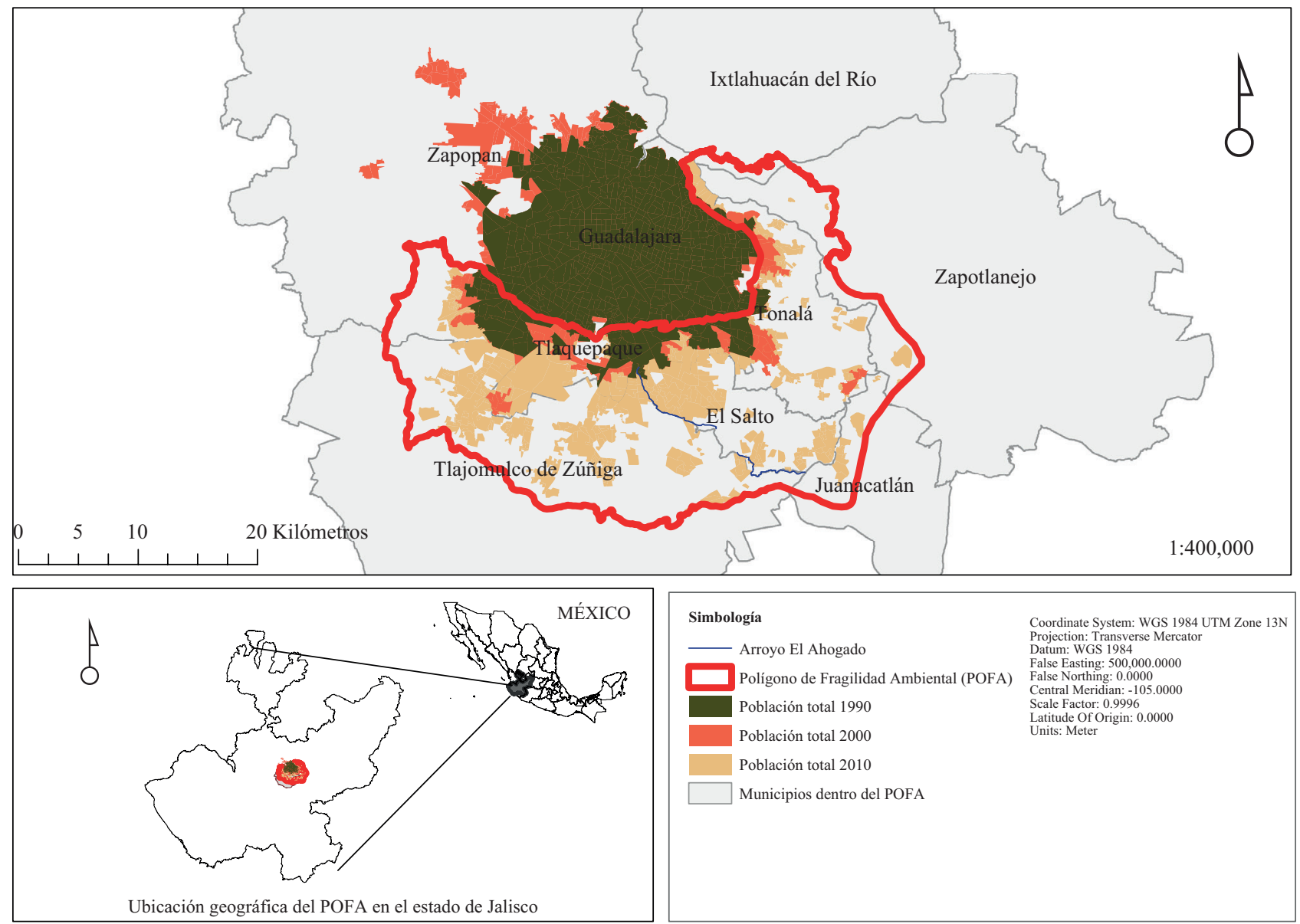

Fuente: elaboración propia con base en SEMADET, 2018 e INEGI, 2010.

Una de ellas ha sido la instalación de la PTAR El Ahogado. Sin embargo, esta solo trata las aguas provenientes del sector doméstico ${ }^{15} \mathrm{y}$ no las que se producen en la industria. Por lo tanto, las aguas superficiales se convierten en receptoras de los residuos que producen la industria textil, electrónica, farmacéutica, automotriz y papelera, por mencionar solo algunos de los ramos industriales.

A inicios del siglo XX, la presa El Ahogado recibía los escurrimientos de toda la cuenca El Ahogado, flujos que eran canalizados a través de presas y utilizados en la agricultura. Posteriormente, en la década de 1970, esta actividad fue sustituida por la industria, que comenzó a verter sus aguas residuales a los distintos cuerpos de agua, entre ellos al afluente en cuestión ${ }^{16}$ (Mapa 2).

En la imagen podemos observar y hacernos una idea de la importancia que tenían los escurrimientos de agua en la cuenca El Ahogado y en el POFA. El sistema de presas (17 en total) se utilizaba para impulsar

\footnotetext{
15. Comisión Estatal del Agua, 2017.

16. Secretaría de Agricultura y Recursos Hidráulicos, Subsecretaría de Planeación, 1980.
}

actividades agropecuarias antes de la década de 1970. En la actualidad, el agua de 11 de estos 17 embalses $^{17}$ es utilizada para la siembra y crianza de ganado. Ya que algunos de estos afluentes reciben aguas residuales provenientes de asentamientos humanos y de empresas manufactureras ${ }^{18}$ (2.848 en total) la pregunta que nos hacemos es la siguiente: ¿qué calidad de agua se almacena en estos embalses? Como la presa El Ahogado (en el Mapa 2 se puede observar en círculo negro) es el punto geográfico más bajo del sistema hídrico y recibe todos los desechos que se generan aguas arriba.

\footnotetext{
17. El resto de las presas se distribuyen de la siguiente forma: tres son requeridas para la generación de electricidad, dos no tienen datos y una es utilizada para el almacenaje de agua potable (Las Pintas). http://sina. conagua.gob.mx/sina/tema.php?tema=presasPrincipales

18. Por el momento, solo se analizaron estas actividades productivas: alimenticia, metal-mecánica, textil, química, transportes y electrónica. Las mismas van desde micro, pequeña, mediana y gran empresa. El actual gobierno de Jalisco reconoce a estas actividades productivas como las generadoras de residuos, emisiones y descargas, incumpliendo con el marco legal y normativo. https://www.jalisco.gob.mx/es/gobierno/ comunicados/revive-el-rio-santiago-con-la-estrategia-integral-para-su-recuperacion
} 
Mapa 2. Ubicación de presas en el POFA

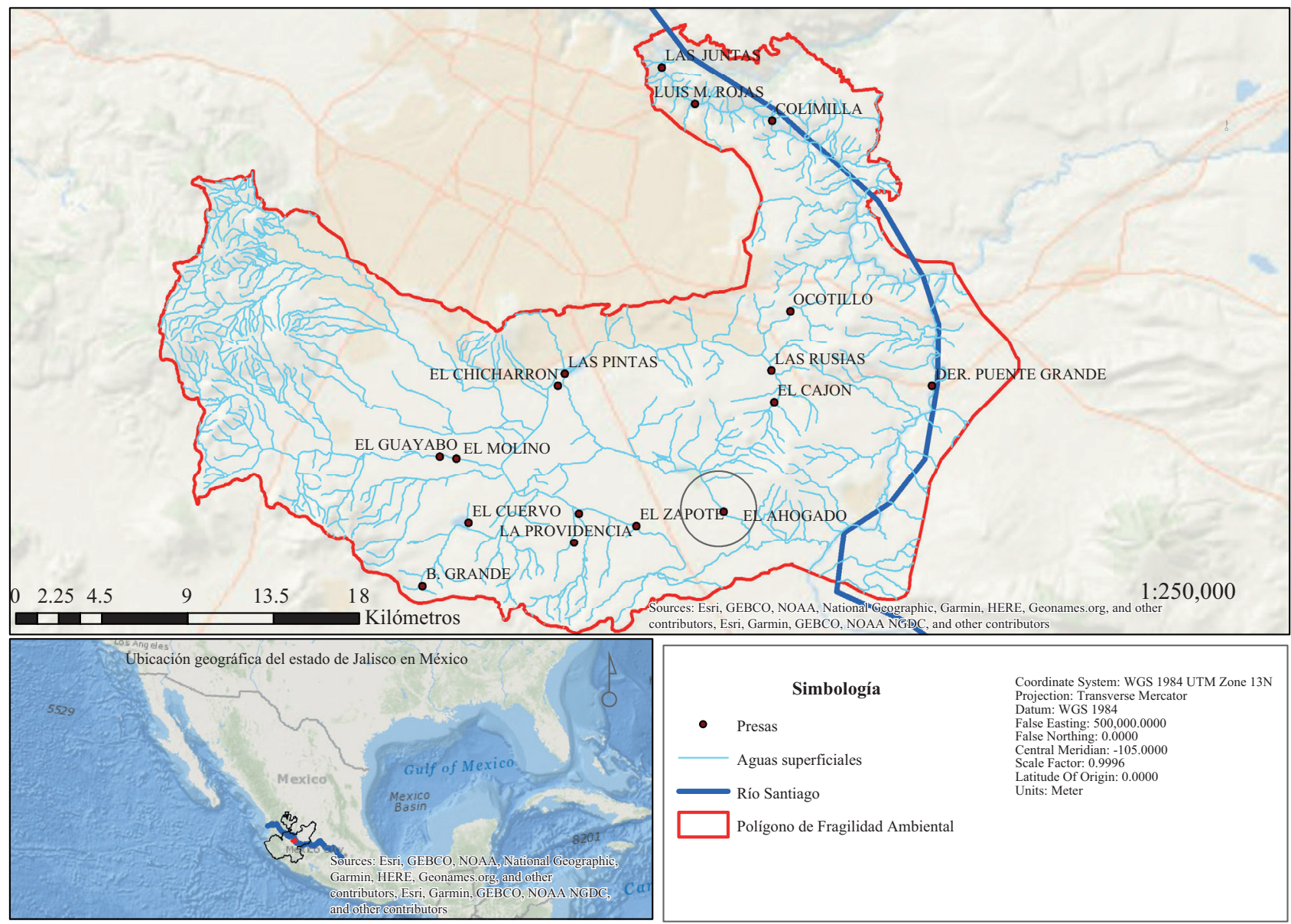

Fuente: Elaboración propia con base en la página web de la CONAGUA (http://sina.conagua.gob.mx/sina/tema.php?tema=presasPrincipales)

Estas desatenciones han provocado un gran deterioro ambiental en el territorio, presente en la parte baja del mismo, donde se encuentra el arroyo y la presa El Ahogado. A ello hay que sumar que "estas áreas se han convertido en espacios donde crece la violencia a causa de deficientes o nulos servicios de seguridad, transporte, iluminación, así como a la ausencia de oportunidades productivas, educativas y deportivas para los jóvenes que ahí habitan"19.

Este vaso regulador recibe las aguas sin tratamiento provenientes de los sectores antes mencionados, y se considera una de las fuentes principales de la contaminación del río Santiago ${ }^{20}$. El decreto del POFA debería decirnos, por sí solo, que existe un problema ambiental y que debería atenderse de inmediato. En este espacio viven cerca de millón y medio de pobladores. Por lo tanto,

\footnotetext{
19. Torres Rodríguez, 2018, 32.

20. La contaminación del río Santiago ha sido la causa de sus padecimientos y está relacionada con la actividad industrial que se desarrolla en los estados de Guanajuato, Jalisco, Michoacán y Estado de México. González, 1987. Durán y Torres, 2009. McCulligh, Tetreault y Martínez, 2012. Ochoa García, 2012.
}

es necesario conocer y analizar los trabajos que se han realizado sobre la calidad del agua en dicha zona para valorar el riesgo al que se ven sometidos sus habitantes.

\section{Análisis de la calidad de agua en la parte baja del POFA: la presa El Ahogado}

Este embalse es el punto más bajo de la cuenca El Ahogado y es alimentada por el arroyo del mismo nombre, que nace en la presa de Las Pintas de Abajo, en el municipio de Tlaquepaque. Su recorrido es de $8,8 \mathrm{~km}$ desde su nacimiento hasta llegar a la parte baja de la cuenca hidrológica. El afluente recibe las aguas residuales que se producen en los sectores agrícola ${ }^{21}$, urbano e indus-

\footnotetext{
21. "Las inversiones para el campo desde entonces y hasta finales de los ochenta siempre se destinaron al apoyo para el desarrollo de zonas de riego en cuanto a su tecnificación e inversión en tecnologías para la mejora de los cultivos y obtención de mayores rendimientos económicos, a pesar de que paulatinamente se descuidó también a esta actividad”. Rojas Ramírez, 2018, 99.
} 
Tabla 1. Estudios de la calidad del agua en la presa El Ahogado, vaso regulador del POFA

\begin{tabular}{|c|c|c|c|}
\hline Análisis & Autor (es) & Año & Contaminantes detectados en cuerpo de agua \\
\hline 1 & $\begin{array}{l}\text { Secretaría de Agricultura y Recursos Hidráulicos } \\
\text { (SARH) }\end{array}$ & 1980 & Aceites, fertilizantes y descargas domésticas. \\
\hline 2 & $\begin{array}{l}\text { Comisión Estatal del Agua (CEA) y AyMa Ingeniería y } \\
\text { Consultoría S.A. de C.V. }\end{array}$ & 2006 & Cadmio, cobre, cromo, mercurio, níquel y plomo. \\
\hline 3 & McCulligh, Páez y Moya & 2007 & $\begin{array}{l}\text { Demanda bioquímica de oxígeno, demanda química de oxígeno y } \\
\text { nitrógeno amoniacal. }\end{array}$ \\
\hline 4 & Arellano Aguilar, Ortega Elorza y Gesundheit Montero & 2012 & Bario, cromo, hierro, mercurio y zinc. \\
\hline 5 & Arellano Aguilar, Ortega Elorza y Gesundheit Montero & 2013 & Arsénico, cadmio, cromo, mercurio, plomo y níquel. \\
\hline 6 & Greenpeace & 2016 & $\begin{array}{l}\text { Nonifenol, ftalatos, octifenol y el bisfenol, productos químicos } \\
\text { utilizados en industrias como detergentes, retardantes de flama y } \\
\text { elaboración de plásticos. }\end{array}$ \\
\hline 7 & CEA & 2009-2017 & Aluminio, bario, cromo, hierro, mercurio y zinc. \\
\hline
\end{tabular}

Fuente: elaboración propia, 2018.

trial, generadas en la parte alta de la cuenca. De esta forma, la parte baja recibe las aguas residuales que se producen aguas arriba (Tabla 1 ).

Estos estudios fueron realizados por distintas instituciones, tanto privadas como públicas, así como por investigadores académicos, quienes han identificado diversos contaminantes ${ }^{22}$. En esta revisión podemos observar que, desde la década de 1980 hasta la actualidad, el embalse ha recibido aguas residuales provenientes de los sectores urbano e industrial $^{23}$.

En el año 1980 la SARH realizó un estudio de la calidad del agua en dicho embalse. Este organismo encontró varias fuentes contaminantes, entre ellas, la aceitera La Reforma (aceite comestible y forrajes), una maquiladora de oleaginosas (aceite comestible), Guanomex (fertilizantes) y el aeropuerto de Guadalajara (tipo doméstica). Estas dos últimas descargas son vertidas al arroyo La Colorada, que a su vez desemboca en el cuerpo de agua en cuestión. Esto sucede durante el temporal de lluvias, cuando el flujo es suficiente ${ }^{24}$. En tiempo

\footnotetext{
22. El trabajo de Marques Harres (2018) nos muestra un proceso de construcción histórica en lo referente a la degradación de una cuenca. Nos habla de la contaminación de la cuenca hidrográfica del río de los Sinos, en Brasil. Además, se documenta la degradación ambiental desde fines del siglo XIX hasta el año 2017. El crecimiento urbano y el de la industria, el desplazamiento y las afectaciones de la agricultura son algunos de los cambios en la población y la cuenca.

23. Por el momento no se profundizó en el tema agrícola, presente en esta parte del territorio, porque nos limitamos a comprender los efectos que produce la actividad industrial en el medio ambiente, más concretamente en el agua superficial.

24. Secretaría de Agricultura y Recursos Hidráulicos, Subsecretaría de Planeación, 1980.
}

de estiaje se generen encharcamientos, malos olores y reproducción de mosquitos ${ }^{25}$.

En el año 2006 la CEA, junto a la empresa AyMA Ingeniería y Consultoría S.A. de C.V., realizaron análisis de calidad del agua en el río Santiago; entre el lago de Chapala y el río Verde, en el río Zula; entre los municipios de Arandas y Ocotlán, y en el Arroyo Chico; entre el municipio de Tototlán y el río Zula. Esta investigación tenía por objetivo identificar y caracterizar las fuentes de contaminación en dichos afluentes. La investigación involucró a 13 municipios ${ }^{26}$. Uno de sus resultados dictaminó que:

"El arroyo El Ahogado es, en la situación actual, una fuente de contaminación del río Santiago [...] los vertidos de agua residual de las múltiples industrias asentadas en la margen izquierda de la presa del Ahogado, así como las situadas aguas debajo de la presa, son los probables causantes de esta desfavorable condición de las aguas conducidas por el arroyo" ${ }^{27}$.

Lo anterior nos demuestra que la autoridad gubernamental, encargada del estudio de calidad del agua superficial, a pesar de los resultados negativos obtenidos, usa el calificativo de "probable causante", lo que nos parece carente de responsabilidad social. A continuación, observaremos una tabla que nos muestra el problema ambiental presente en el ecosistema y en la vida de los

\footnotetext{
25. Con base en distintas charlas informales sostenidas con los propios habitantes en diversos exploratorios de las localidades de La Huizachera, Villas de la Alameda, El Salto, La Azucena y Jardines del Castillo.

26. Arandas, Atotonilco, Ocotlán, Tototlán, Poncitlán, Zapotlán del Rey, Chapala, Ixtlahuacán de los Membrillos, Juanacatlán, Tlajomulco, El Salto, Zapotlanejo y Tonalá.

27. Comisión Estatal del Agua y AyMA, 2006, 34 y 40.
} 
Tabla 2. Calidad del agua antes y después de la PTAR El Ahogado

\begin{tabular}{|c|c|c|c|c|}
\hline \multicolumn{5}{|c|}{ Aguas arriba de El Ahogado } \\
\hline Conductividad & $\begin{array}{l}\text { Sólidos Suspendidos } \\
\text { Totales (SST) }\end{array}$ & $\begin{array}{l}\text { Demanda Bioquímica de Ox- } \\
\text { igeno }\left(\mathrm{DBO}_{5}\right)\end{array}$ & Nitrógeno Total & Fósforo Total \\
\hline Contaminado & Excelente & Severamente contaminado & Severamente contaminado & Severamente contaminado \\
\hline \multicolumn{5}{|c|}{ Aguas abajo de El Ahogado } \\
\hline Conductividad & $\begin{array}{l}\text { Sólidos Suspendidos } \\
\text { Totales (SST) }\end{array}$ & $\begin{array}{l}\text { Demanda Bioquímica de Ox- } \\
\text { igeno }\left(\mathrm{DBO}_{5}\right)\end{array}$ & Nitrógeno Total & Fósforo Total \\
\hline $\begin{array}{l}\text { Ligeramente contam- } \\
\text { inado }\end{array}$ & Aceptable & Severamente contaminado & Severamente contaminado & Severamente contaminado \\
\hline
\end{tabular}

Fuente: Elaboración propia con base en Comisión Estatal del Agua y AyMa, 2006 y Droste, 1997.

pobladores que residen en la cercanía de este cuerpo de agua. "Los pobladores relatan que antes se podía pescar, así, podemos establecer una relación entre la actual falta de oxígeno en el agua y la desaparición de peces". El cuerpo de agua recorre varias localidades de los municipios de Tlaquepaque y El Salto, y desemboca en la presa El Ahogado, desviándose las aguas residuales del sector doméstico hacía la PTAR, antes de derivarlas hacia el río Santiago (Tabla 2).

Con base en la clasificación del agua superficial, de acuerdo con la concentración de contaminantes ${ }^{28}$, podemos argumentar que cuatro de los cinco parámetros analizados no son aceptables. La conductividad del agua ( $\mu \mathrm{mhos} / \mathrm{cm})$ encontrada en estos dos puntos fue de 1.592 y 1.245 , cuando el valor aceptado es menor a 500. En cuanto al índice máximo de $\mathrm{DBO}_{5}(\mathrm{mg} / \mathrm{l})$ debe ser menor a 1,5, las muestras superaron los 52,0 y 42,9. El nitrógeno total ( $\mathrm{mg} / \mathrm{l})$ en ambas localizaciones fue de 28,10 y 23,65 , y lo permitido es menor a 0,5 . Y por último, el fósforo total ( $\mathrm{mg} / \mathrm{l})$ encontrado en ambos lugares fue de 8,5 y 7,15 , mientras que lo aprobado es menor a 0,05 . Por lo tanto, la calidad del agua en este sistema hídrico: arroyo-presa-arroyo El Ahogado, constituye un riesgo sanitario para las poblaciones cercanas (Mapa 3).

En el mapa podemos observar el área de riesgo ambiental que tendría el arroyo y presa de El Ahogado (degradación descrita en las investigaciones analizadas) a cinco kilómetros de distancia. El alcance abarca los 262,31 $\mathrm{km}^{2}$ distribuidos entre los municipios de Guadalajara, Tlaquepaque, Tlajomulco de Zúñiga, El Salto y Juanacatlán. En medio de la posible afectación se encuentran casi ciento cincuenta mil habitantes distribuidos a lo largo de los 8,8 kilómetros de la extensión del afluente (así como los trabajadores y visitantes del aeropuerto internacional de Guadalajara).

\footnotetext{
28. Adaptado por la CEA de Droste, 1997.
}

No hay que olvidar que dichos escurrimientos se vierten hacia el río Santiago, donde se encuentran otras poblaciones (Mapa 4). En esta representación gráfica se coloca en conjunto al arroyo El Ahogado y el río Santiago en el POFA, considerada una zona de afectación que abarca cinco kilómetros a los márgenes de cada afluente. Por lo tanto, más de medio millón de habitantes estarían en situación de riesgo por el hecho de vivir en las cercanías de estos cuerpos de agua contaminados.

La crisis ambiental está presente en las nuevas desigualdades sociales a escala global. Surgen en situaciones de clase y las situaciones de riesgo se disfrazan ${ }^{29}$. En este caso las autoridades municipales agregan a más pobladores a vivir bajo esta crisis ambiental. Es decir, permiten a las inmobiliarias construir en estos espacios de marginación, contaminación y alejados del centro de la ciudad de Guadalajara. El municipio de Tlajomulco de Zúñiga (por poner un ejemplo) ha mostrado la mayor tasa de crecimiento (12,92 \%) en el periodo 2000-2010, a diferencia del resto de los municipios metropolitanos (El Salto 5,18 \%, Tonalá 3,57 \%, Tlaquepaque 2,52 \%, Zapopan $2,19 \%$ y Guadalajara $-0,96 \%$ ).

El gobierno municipal recibe la petición de urbanizar por parte de una inmobiliaria (con capital privado), a la cual se le solicita un plan de ordenamiento y si este lo avala, se construyen viviendas en masa. Por ejemplo, tan solo en el año 2006, el gobierno municipal de Tlajomulco de Zúñiga autorizó a diversas empresas privadas la construcción de 53.798 viviendas ${ }^{30}$. Si hacemos una estimación con respecto al promedio de habitantes en la vivienda del año 2000, que fue de $4,4^{31}$, estaríamos hablando de que este municipio recibió más de doscien-

\footnotetext{
29. Beck, 1986, 47.

30. Datos proporcionados por el ayuntamiento de Tlajomulco de Zúñiga a través de la Unidad de Transparencia, oficio DGT/1734/2016.

31. Instituto Nacional de Estadística y Geografía, 2000.
} 
Mapa 3. Riesgo ambiental del Arroyo El Ahogado

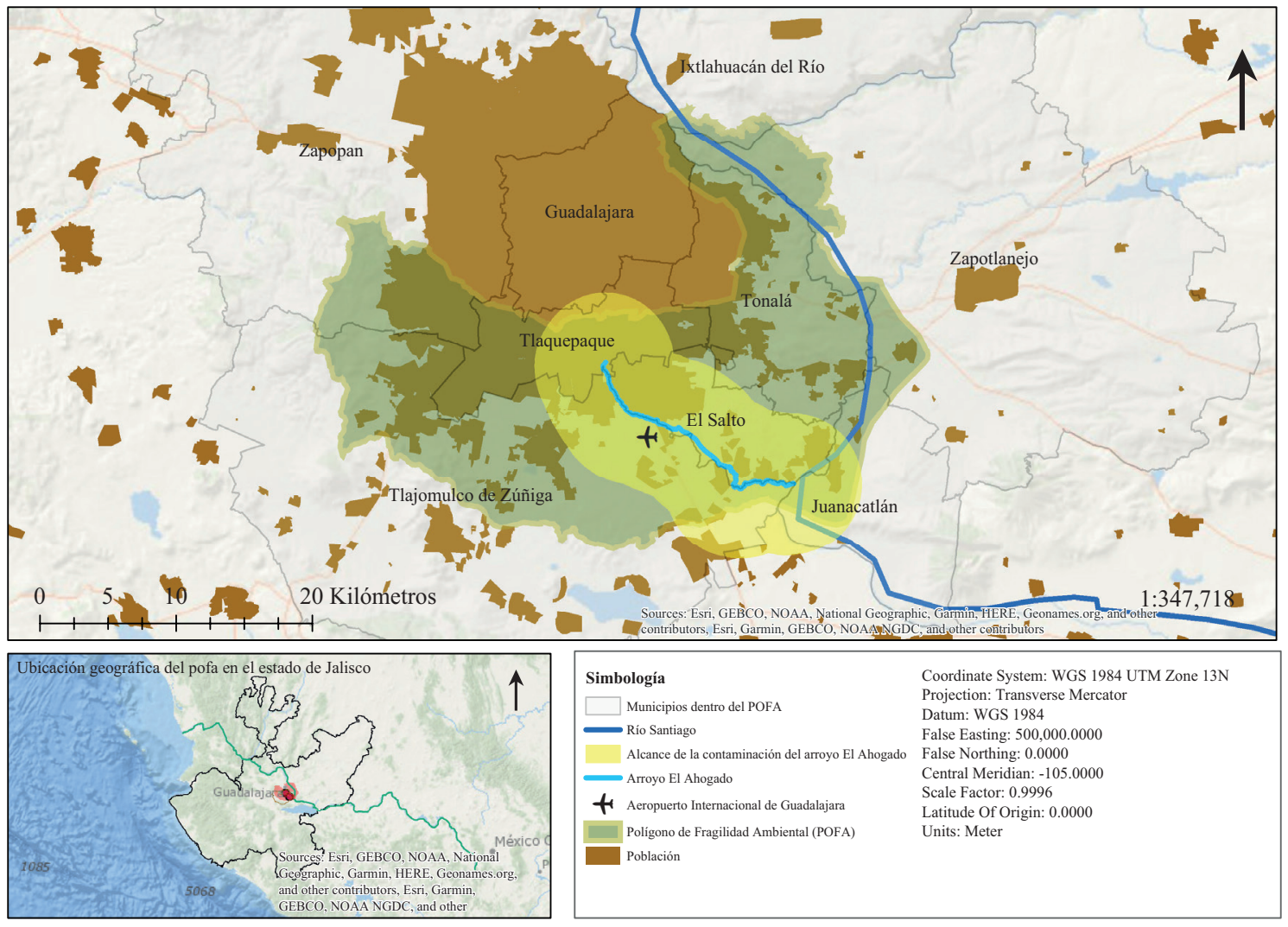

Fuente: elaboración propia con base en las páginas web del Estado de Jalisco. https://datos.jalisco.gob.mx/dataset/ grado-de-marginacion-por-colonia y SEMADET http://sigat.semadet.jalisco.gob.mx/mxsig/

Mapa 4. Riesgo ambiental del Arroyo El Ahogado y el río Santiago

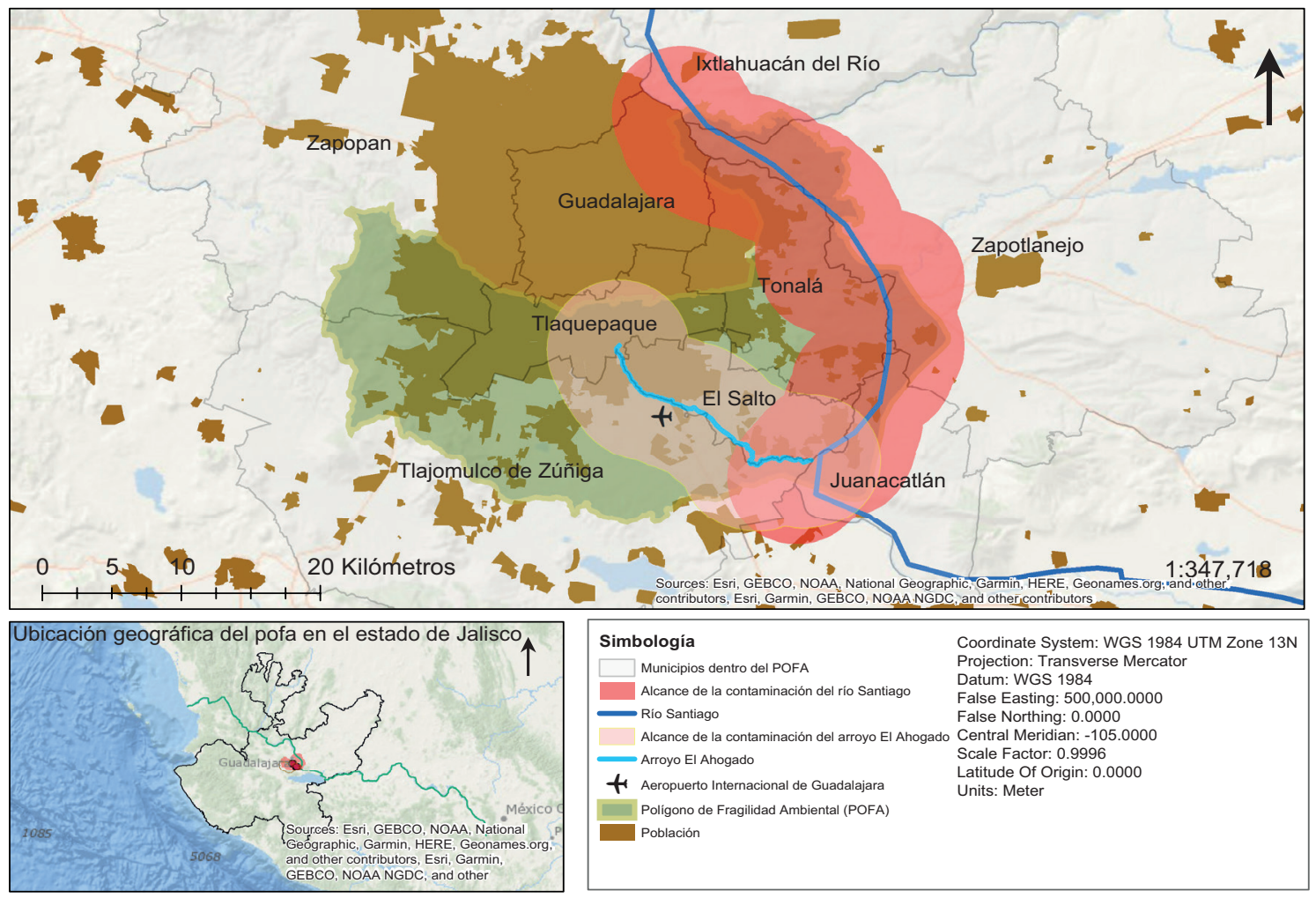

Fuente: elaboración propia con base en las páginas web del Estado de Jalisco https://datos.jalisco.gob.mx/dataset/ grado-de-marginacion-por-colonia y SEMADET http://sigat.semadet.jalisco.gob.mx/mxsig/ 
tos mil habitantes en un solo año. Esto representa un impacto en la infraestructura urbana y en la demanda de servicios básicos: agua, luz, drenaje, escuelas, transporte público y servicios de salud.

En el año 2007 se publicó "Los Mártires del Río Santiago”, de Cindy McCulligh, Juan Carlos Páez y Gerardo Moya. El artículo fue editado por el Instituto Mexicano para el Desarrollo Comunitario (IMDEC) A.C., en colaboración con el Instituto de Valores Integrales y Desarrollo Ambiental A. C. Esta investigación formó parte de la denuncia ciudadana del deterioro ambiental del río Santiago ante la Comisión Estatal de Derechos Humanos Jalisco (CEDHJ). Este fue el precedente para sentar las bases de la Macro recomendación ${ }^{32}$ emitida en el año 2009 por esta organización defensora.

La investigación se divide en cuatro apartados. El primero tiene que ver con la recolección y resumen de datos existentes de la contaminación del río Santiago, grado y fuentes contaminantes. Asimismo, se presentan los estudios realizados en cuanto a los daños a la salud entre la población a causa de la degradación ambiental y las acciones realizadas por parte de las organizaciones sociales. El segundo, resume las evidencias que muestran las violaciones a los derechos humanos en cuanto a la privación de un medio ambiente sano y la salud. El tercero se refiere a las obligaciones que tiene el Estado en hacer que se cumplan estos derechos, presentes en las leyes y en otros instrumentos jurídicos. Por último, se emiten una serie de recomendaciones para atender y resolver la situación que padecen los pobladores.

Se realizó un análisis del Índice de Calidad de Agua (ICA) en varios afluentes vinculados con el río Santiago. Para ello se recurrió a la normativa de la Secretaría de Medio Ambiente, Recursos Naturales y Pesca (SEMARNAP), con base en el análisis de 18 parámetros como el oxígeno disuelto, coliformes, grasas y aceites, demanda bioquímica de oxígeno, detergentes, sustancias activas al azul de metileno, por mencionar solo algunos de ellos ${ }^{33}$.

Una de las investigaciones ${ }^{34}$ analizadas en este proyecto determinó que el ICA del arroyo El Ahogado, an-

\footnotetext{
32. Por la violación de los derechos humanos a gozar de un ambiente sano y ecológicamente equilibrado, a la salud, al agua, a la alimentación, al patrimonio, a la legalidad, a la seguridad social, al desarrollo sustentable, a la democracia, al trabajo, a tener una vivienda en un entorno digno, los derechos de niñas y niños a un nivel de vida adecuado para su desarrollo físico, espiritual, moral y social. http://semadet.jalisco.gob.mx/sites/semadet.jalisco.gob.mx/files/ resumen_de_antecedentes.pdf, consultado el 16 de noviembre de 2017.

33. McCulligh, Páez y Moya, 2007, 18.

34. Elaborado en junio del 2004 por el Laboratorio del Grupo Microanálisis S. A. de C. V., a solicitud del empresario jalisciense y presidente de Fundación Cuenca Lerma Chapala Santiago A. C., Manuel Villagómez, de acuerdo con la NOM-127-SSA1-1994.
}

tes de llegar a la presa, obtuvo una calificación de 29,57. Mientras que, a la salida de dicho embalse, el parámetro fue superior: 31,11 . Con base en el siguiente cuadro y los parámetros correspondientes, el afluente obtendría un calificativo de "contaminación en exceso" (0-40) y sus aguas no serían aptas para el tratamiento potabilizador, de acuerdo con la Comisión Nacional del Agua (CNA) ${ }^{35}$ (Tabla 3).

\section{Tabla 3. Índice de Calidad de Agua (ICA) de la Comisión} Nacional del Agua

\begin{tabular}{lll}
\hline Rango & Criterio general & Clasificación \\
\hline $90-100$ & Excelente Calidad & $\begin{array}{l}\text { No requiere purificación para su } \\
\text { consumo }\end{array}$ \\
\hline $80-90$ & Calidad Aceptable & Requiere purificación menor \\
\hline $70-80$ & Contaminado Leve & $\begin{array}{l}\text { Dudoso su consumo sin } \\
\text { purificación }\end{array}$ \\
\hline $50-70$ & Contaminado & $\begin{array}{l}\text { Tratamiento de potabilización } \\
\text { indispensable }\end{array}$ \\
\hline $40-50$ & Contaminado Fuerte & Dudoso para consumo \\
\hline $0-40$ & Contaminado en Exceso & Inaceptable para consumo \\
\hline
\end{tabular}

Fuente: McCulligh, Páez y Moya, 2007.

En este caso los parámetros de contaminación fueron menores al entrar a la presa y superiores al salir de la misma (ambos estándares son inaceptables para el consumo). Esto nos demuestra que las aguas residuales que se generan en el corredor industrial de El Salto como lo señala la Comisión Estatal del Agua, aumentan el grado de contaminación antes de llegar al río Santiago $^{36}$.

Se realizaron dos muestreos en el arroyo El Ahogado, tanto en temporada de estiaje como en la de lluvia. En el primero se encontraron los siguientes resultados: Demanda Química de Oxígeno (DQO ${ }_{5}$ ) 43,0 mg/l (severamente contaminado); Demanda Bioquímica de Oxígeno (DBO) 176,0 mg/l (severamente contaminado) y nitrato amoniacal $25,60 \mathrm{mg} / \mathrm{l}$ (severamente contaminado). En el segundo, y a pesar de mostrar valores menores al primero, la calidad del agua mostró parámetros negativos: $\mathrm{DQO}_{5} 24,4 \mathrm{mg} / \mathrm{l}$ (severamente contaminado); DBO 135,0 mg/l (severamente contaminado) y nitrato amoniacal $8,53 \mathrm{mg} / \mathrm{l}$ (severamente contaminado ${ }^{37}$. Este proyecto sostiene que las descargas industriales hacia el río Santiago se encuentran en tres lugares: la ciudad de Ocotlán, el corredor industrial de

\footnotetext{
35. McCulligh, Páez y Moya, 2007.

36. Comisión Estatal del Agua y AyMA, 2006.

37. AYMA Ingeniería y Consultoría, 2003.
} 
El Salto y el corredor industrial que se encuentra en el anillo periférico sur de la Zona Conurbada de Guadalajara $^{38}$. A nuestro entender, estas dos últimas concentraciones industriales son el problema fundamental de la degradación ambiental y son el origen de la etiqueta que pesa al sur de la ZMG.

Se realizó una investigación denominada "Estudio sobre la contaminación en la cuenca del río Santiago y la salud pública en la región" ${ }^{39}$. El trabajo fue auspiciado por parte de Greenpeace, Un Salto de Vida A.C., y la Unión de Científicos Comprometidos con la Sociedad (UCCS). Los análisis de dicha investigación sostienen que la presa $\mathrm{El}$ Ahogado ha presentado los niveles más altos de metales pesados: bario, cromo, hierro, mercurio y zinc. Estos se han detectado por encima del límite máximo establecido en la Ley Federal de Derechos de Agua, $2009^{40}$, constituyendo un riesgo para la población cercana, tal es el caso de las localidades de San José El Quince, San José El Verde, El Refugio, Zapote del Valle, San José del Castillo, La Alameda, La Azucena y los nuevos fraccionamientos ${ }^{41}$.

$\mathrm{Al}$ año siguiente, se publicó otro artículo, el cual tenía como objetivo caracterizar cartográficamente las descargas contaminantes de origen industrial de los distintos cuerpos de agua superficial, con base en el Registro de Emisión y Transferencia de Contaminantes ${ }^{42}$ (RETC). La investigación determinó que las industrias que descargan metales pesados se concentran en tres espacios geográficos: en el centro de las ciudades de Guadalajara, Ocotlán y en la zona de la presa El Ahoga$\mathrm{do}^{43}$ (Mapa 5).

En el Mapa 5 podemos observar en la parte superior izquierda la concentración de la actividad industrial en el municipio de Guadalajara y, un poco más abajo, la presa El Ahogado. Por otra parte, observamos en la parte baja hacia la derecha, el nacimiento del río Santiago en las inmediaciones del Lago de Chapala y el municipio de Ocotlán. Son las zonas con mayor contaminación en el estado de Jalisco ${ }^{44}$. Lo preocupante es que el municipio de Guadalajara no cuenta con planta de tratamiento de aguas residuales, por lo tanto, genera metales pe-

\footnotetext{
38. McCulligh, Páez y Moya, 2007, 11.

39. Arellano Aguilar, Ortega Elorza y Gesundheit Montero, 2012.

40. Por la amplitud del contenido, consultar en: http://www.conagua.gob. mx/CONAGUA07/Publicaciones/Publicaciones/SGAA-37-12.pdf

41. Arellano Aguilar, Ortega Elorza y Gesundheit Montero, 2012, 20.

42. De acuerdo con el estudio, se tienen contempladas 104 sustancias sujetas a reporte en el RETC; inventario de la Secretaría del Medio Ambiente y Recursos Naturales (SEMARNAT). Consultar en https://apps1.semarnat. gob.mx:8443/retc/retc/index.php

43. Arellano Aguilar, Ortega Elorza y Gesundheit Montero, 2013, 155.

44. Arellano Aguilar, Ortega Elorza y Gesundheit Montero, 2013.
}

sados para el río Santiago, aguas abajo del POFA. Esto lleva a cuestionar la función y el costo de la PTAR El Ahogado.

Los investigadores revisaron 21.956 cédulas de operación anual, correspondientes a industrias individuales, de las cuales $2.510(11,4 \%)$ reportaron al RETC. Las sustancias que se adhieren a este registro se clasifican en ocho clases: sustancias agotadoras de la capa de ozono (SAO), compuestos orgánicos persistentes (COP), metales y sus compuestos, gases de efecto invernadero (GEI), hidrocarburos aromáticos y alifáticos, sustancias organohalogenadas, plaguicidas y otras sustancias tóxicas $^{45}$. Los resultados de la investigación señalan que, en esos tres espacios, se han encontrado metales pesados como el bario, cromo, hierro, mercurio y zinc. Estas sustancias químicas han estado por encima del límite máximo establecido en la Ley Federal de Derechos de Agua $2009^{46}$. Además, en la zona de estudio se han reportado 1.090 diferentes sustancias tanto en las descargas industriales como en el río Grande de Santiago ${ }^{47}$. La problemática ambiental no solo se limita a estas tres áreas geográficas, estamos frente a un problema interestatal (involucra a cinco estados: Jalisco, Michoacán, Guanajuato, Estado de México y Nayarit) y de afectación global (Mapa 6).

En el Mapa 6 observamos la concentración de actividades manufactureras a lo largo de los ríos Lerma y Santiago. Se realizó un cálculo para contabilizar el total de empresas manufactureras ${ }^{48}$ (textil, química, plástica, papelera, metal-mecánica, electrónica, alimenticia y transporte) a dos kilómetros de distancia de cada afluente $^{49}$. En suma, se encontraron 3.073 empresas distribuidas de la siguiente manera, Estado de México: 1.374, Guanajuato: 799, Jalisco: 506, Michoacán: 237, y Nayarit: 157. Como podemos ver, la actividad industrial se inicia en el Estado de México y pasa por los demás estados, que vierten sus residuos hasta su desembocadura en el océano Pacífico.

En enero de 2016, Greenpeace México acudió a las cercanías de la presa El Ahogado para tomar una serie de muestras de aguas residuales de la PTAR El Ahogado. Las pruebas obtenidas fueron enviadas para su análisis a

\footnotetext{
45. Arellano Aguilar, Ortega Elorza y Gesundheit Montero, 2013, 159.

46. Arellano Aguilar, Ortega Elorza y Gesundheit Montero, 2013, 166.

47. Instituto Mexicano de Tecnología del Agua, 2011.

48. Se realizó un conteo total de los cuatro tamaños de industria: micro, pequeño, mediano y grande.

49. Por considerar que las empresas vierten sus aguas residuales a los cuerpos de agua superficiales. Esto con base en la observación de las empresas de Jalisco. Sin considerar que los escurrimientos lejanos puedan conducir residuos de empresas más lejanas.
} 
Mapa 5. Descargas industriales (color verde) y municipales (color rojo) durante el periodo 2004-2009

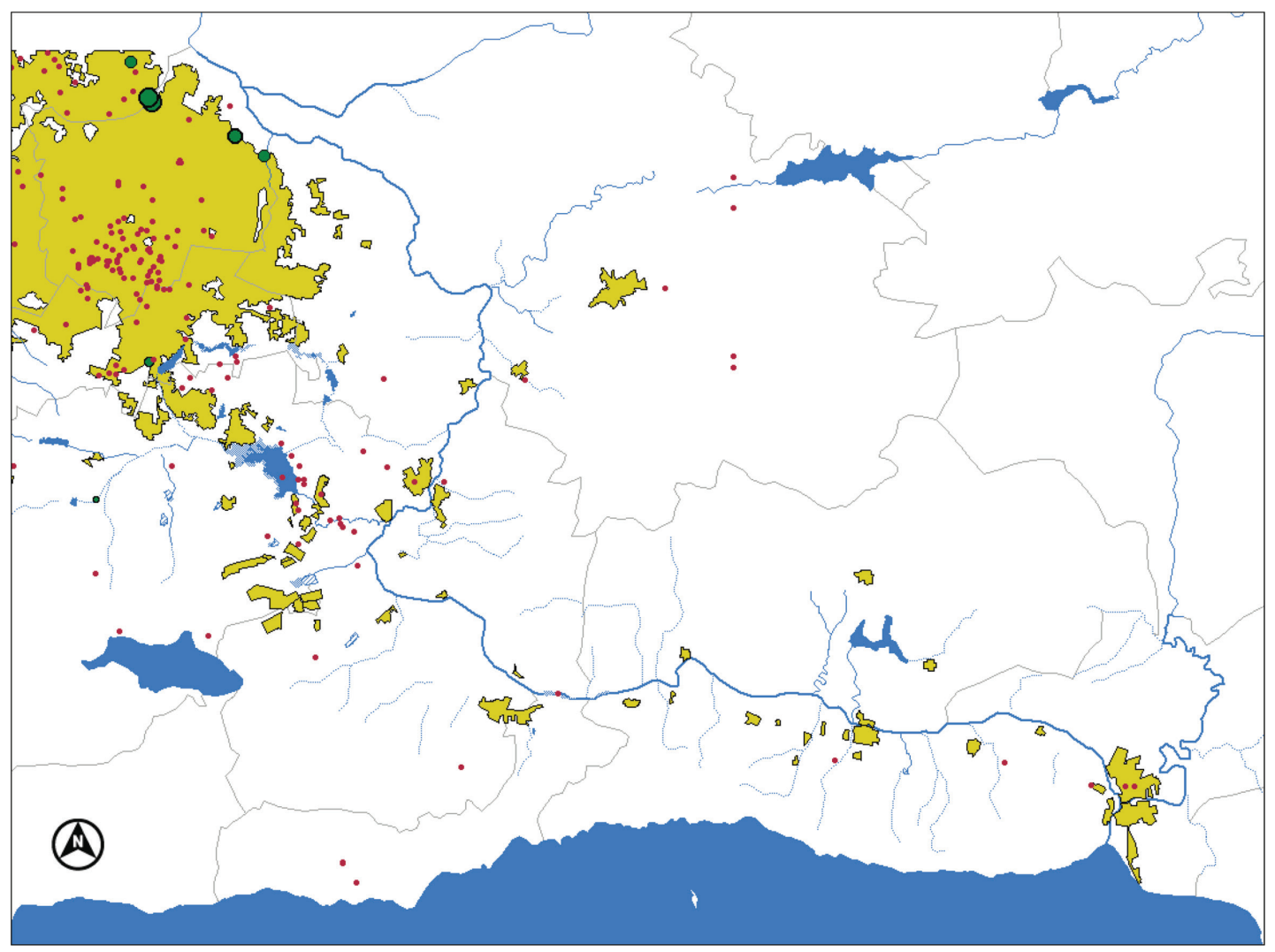

Fuente: Arellano Aguilar, Ortega Elorza y Gesundheit Montero, 2013, 159.

Mapa 6. Empresas manufactureras en las cercanías de los ríos Lerma y Santiago

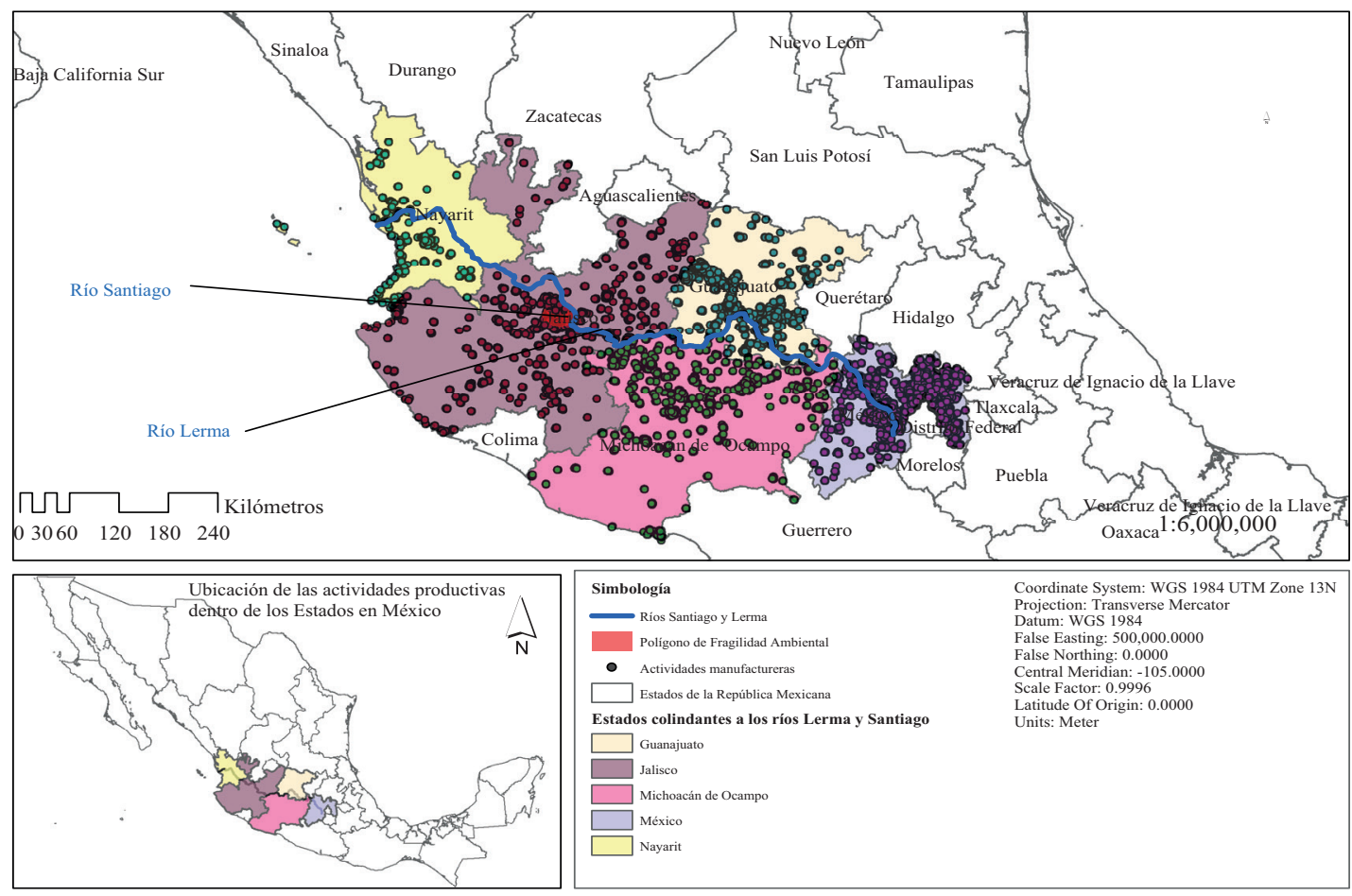

Fuente: elaboración propia con base en la página web del DENUE. https://www.inegi.org.mx/app/mapa/denue/ 
los laboratorios de investigación de Greenpeace en la Escuela de Biociencias de la Universidad de Exeter en Reino Unido $^{50}$. Tras el análisis "se identificó una amplia gama de sustancias químicas orgánicas y metales pesados, lo que exhibe los pobres resultados y las soluciones paliativas que ofrecen las plantas de tratamiento cuando la solución sería atacar el problema de fondo: la descarga de sustancias tóxicas en el agua" ${ }^{51}$. Las muestras de agua extraídas del afluente del cárcamo y sedimentos del arroyo El Ahogado "exhiben la presencia de sustancias tóxicas para la vida acuática y la salud de las personas (cloroformo, ftalatos, 1,4 diclorobenceno, nonifenol, PFC). No queda claro cuál es la fuente exacta de los contaminantes encontrados en el río y sus sedimentos y si estos se dirigen hacia la planta de tratamiento El Ahogado" ${ }^{25}$.

Asimismo, la Secretaría de Salud Jalisco (SSJ) emitió dos oficios referentes al arroyo El Ahogado. El primero de ellos señalaba que jóvenes y niños se bañaban en este afluente contaminado. Para ello se pedía la colaboración de las autoridades municipales a fin de poder alertar a la población. Por último, se solicitó la participación de las cuatro regiones metropolitanas de esta secretaría, entre ellas las áreas de epidemiología, con el objeto de determinar el grado de riesgo para la población en contacto con ese arroyo ${ }^{53}$. Estos resultados nos muestran que el problema ambiental no solo existe en las localidades de las cabeceras (El Salto y Juanacatlán), sino en todo el POFA. Por lo tanto, las localidades cercanas al arroyo El Ahogado se encuentran en riesgo y también aquellas que se ubican en la desembocadura de dicho afluente.

En este último análisis nos dimos a la tarea de examinar los monitoreos realizados por la CEA sobre la calidad del agua en la presa El Ahogado en el periodo 2009-2017 ${ }^{54}$. Estas acciones se han llevado a cabo por las exigencias de la Macro recomendación emitida por la Comisión Estatal de Derechos Humanos. La dependencia estatal encargada del saneamiento del agua tiene diversos puntos de muestreo situados a lo largo del río Santiago, por lo regular cercanos a complejos urbano-industriales. Uno de sus estudios se localiza en el arroyo El Ahogado, antes y después de salir de la presa en cuestión (Mapa 7).

En el Mapa 7 podemos apreciar la conexión existente entre los puntos de muestreo antes de su salida hacia el

\footnotetext{
50. Greenpeace, 2016, 3.

51. https://cronicadesociales.org/2018/02/14/la-azucena-la-historia-quese-detuvo-hace-diez-anos/

52. Greenpeace, 2016.

53. Consejo Estatal de Ciencia y Tecnología del Estado de Jalisco, 2012, 11.

54. http://info.ceajalisco.gob.mx/sca/
}

río Santiago. El primero de ellos se localiza en la carretera a Chapala (triángulo amarillo) frente al aeropuerto internacional de Guadalajara. Y el segundo (triángulo verde), aguas abajo en la localidad de El Muey, tras pasar el parque industrial de El Salto (ambas localizaciones en el municipio saltense). La CEA monitoreó la calidad del agua antes de entrar y al salir de la PTAR ${ }^{55}$. Por lo tanto, la degradación ambiental se verá reflejada tanto en los resultados mostrados por la dependencia estatal, como en los estudios analizados. A continuación, se muestra una gráfica en la que se exhiben los parámetros analizados de cinco metales pesados ${ }^{56}$ (bario, cromo, hierro, mercurio y zinc) (Gráfico 1).

Durante el periodo 2009-2017 la CEA tomó 78 muestras de este cuerpo de agua que desemboca en la presa El Ahogado, para después conectarse con el río Santiago. Con base en los lineamientos de calidad del agua de la CONAGUA y la Ley Federal de Derechos, Disposiciones Aplicables en Materia de Aguas Nacionales ${ }^{57}$, la dependencia analizó cerca de cincuenta parámetros en el agua, entre los que se encontraban los siguientes: acidez total, alcalinidad total, cloruro total, color verdadero, conductividad, demanda bioquímica de oxígeno, demanda química de oxígeno, aluminio, bario, cromo, hierro, mercurio, zinc, etc. El zinc es uno de los metales con mayor presencia en este afluente, 72 de 78 análisis se encontraron fuera de norma (0,02 miligramos por litro como límite máximo). El segundo metal presente en los cuerpos de agua fue el mercurio, 33 de 78 muestras estaban fuera de norma (0,0005 miligramos por litro como límite máximo) a la entrada de la presa. Asimismo, a la salida aumentó a 41 tomas desfavorables. El tercer rango más alto lo constituyó el hierro con 38 pruebas fuera del límite permitido. El cuarto es el cromo, que no representa riesgo alguno de acuerdo con los resultados mostrados (cuatro pruebas de riesgo). Y el último es el bario con 48 análisis patógenos $(0,01 \mathrm{mg} / 1$ límite máximo permitido). En la revisión del sistema de calidad del agua de la CEA encontramos otros resultados en los que podemos observar la magnitud del problema ambiental. Por ejemplo, la presencia del aluminio $(0,05$

\footnotetext{
55. En el estudio no se explica la metodología utilizada para elegir estos dos puntos. Para nuestros fines científicos, conocer estos dos puntos -antes de llegar a la planta de tratamiento y a la salida de la misma- nos sirvió para comparar la situación ambiental, junto a los otros trabajos. En la investigación se señalan otros puntos de monitoreo de calidad de agua (15 en total) relacionados con el recorrido del río Santiago y el rio Zula.

56. Este criterio tiene fundamento en las muestras fuera de norma que ha encontrado la Comisión Estatal del Agua (2017) y los trabajos de Arellano Aguilar, Ortega Elorza y Gesundheit Montero (2012 y 2013).

57. https://www.gob.mx/cms/uploads/attachment/file/105137/Ley_Aguas_ Nacionales.pdf
} 
Mapa 7. Puntos de muestreo de la CEA
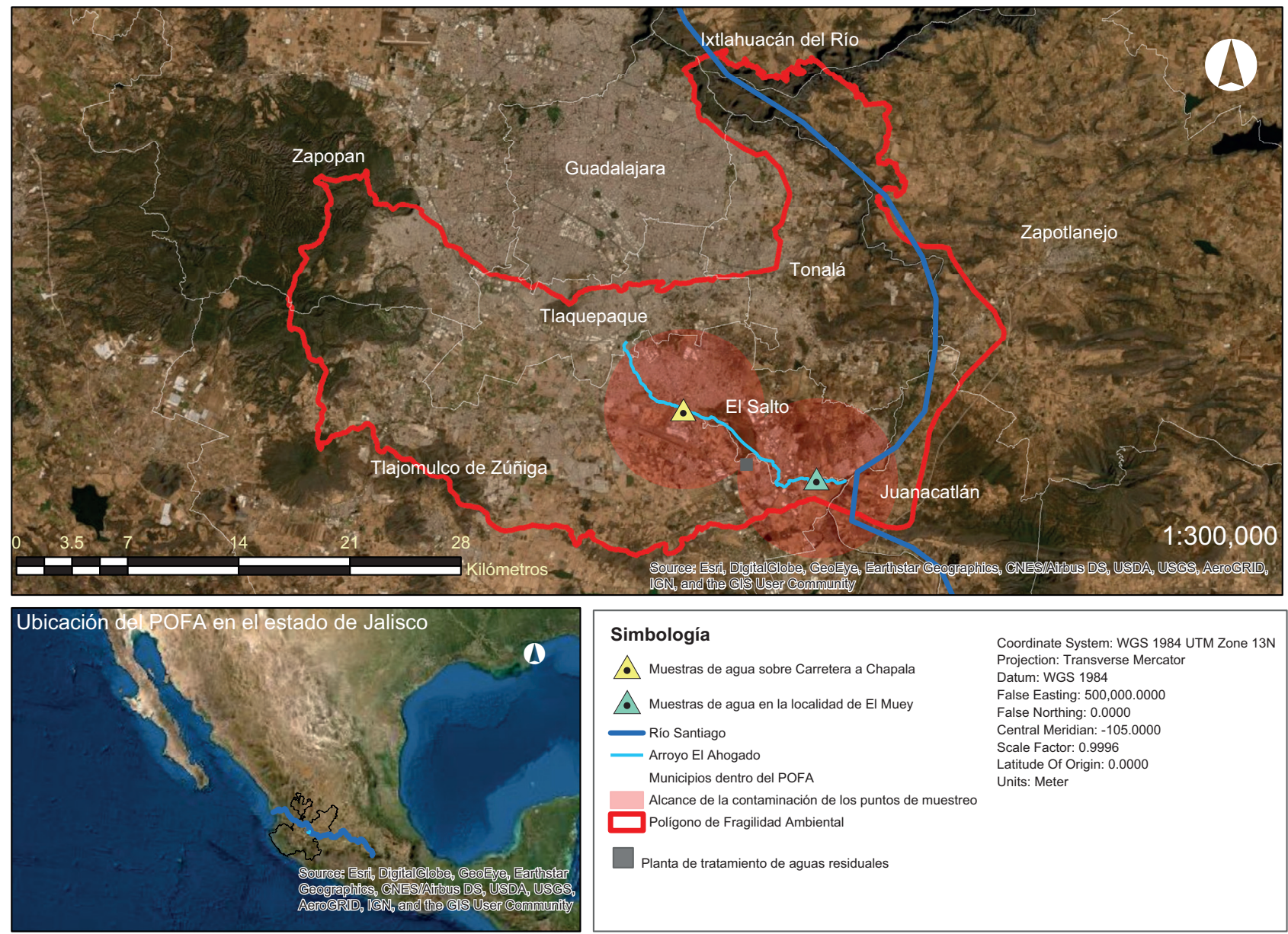
Coordinate System: WGS 1984 UTM Zone 13N Projection: Transverse Mercator
.
False Northing: 0.0000
Scale Factor: 0.9996
Lative of 0 ingin: 0.0000
Units: Meter

Planta de tratamiento de aguas residuales

Fuente: elaboración propia con base en la página web de la CEA http://info.ceajalisco.gob.mx/sca/

Gráfico 1. Parámetros fuera de norma en el arroyo El Ahogado, 2009-2017

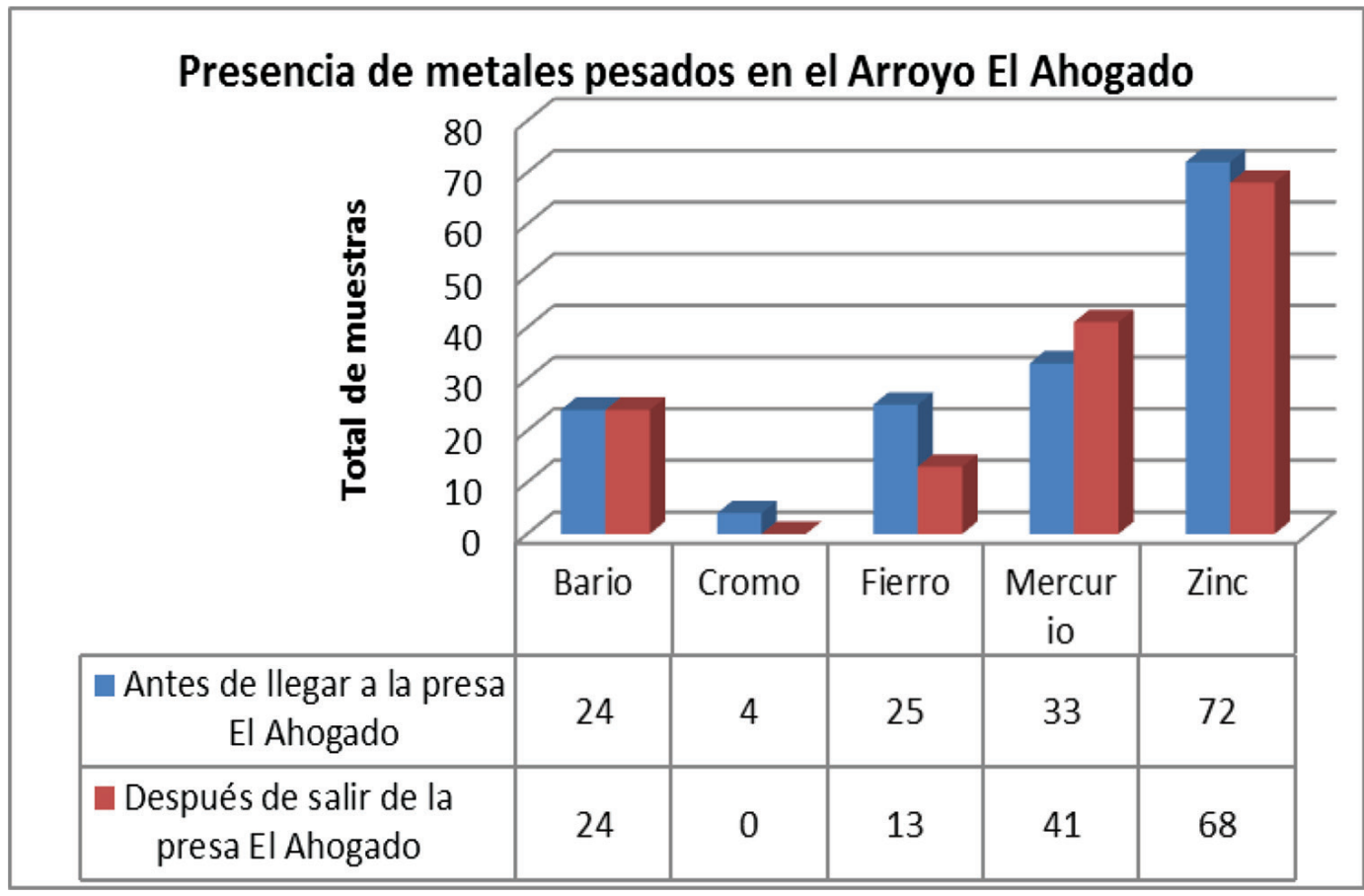

Fuente: elaboración propia con base en los muestreos tomados por la CEA, 2017. 
mg/l máx.), que antes de entrar a la presa, mostró 77 de 78 resultados fuera de norma. Y después de la presa, se hallaron 75 de 78 muestras negativas. El valor máximo encontrado en este afluente fue de $14,64 \mathrm{mg} / \mathrm{l}$, cuando lo permitido es $0,05 \mathrm{mg} / \mathrm{l}$.

Otra de las sustancias químicas presentes en el agua fue el fósforo total, 78 de 78 muestras estaban fuera de norma $(0,05 \mathrm{mg} / \mathrm{l}$ máx.) antes de entrar a la presa y a la salida. Los valores máximos encontrados fueron los siguientes: 11,93 mg/l antes de entrar al embalse y $20 \mathrm{mg} / \mathrm{l}$ a su salida. En lo que respecta a las grasas y aceites, 36 de 78 muestras estaban fuera de norma (10 $\mathrm{mg} / \mathrm{l}$ límite máximo). De igual forma, se encontraron 25 muestras anómalas a la salida de la presa. En cuanto a la $\mathrm{DBO}_{5}, 61$ muestras estaban fuera de norma antes de entrar a la presa (30 $\mathrm{mg} / \mathrm{l}$ máximo). Posterior a esta se encontraron 38 muestras que excedían el límite, con valores superiores a $606 \mathrm{mg} / \mathrm{l}$. Por otra parte, la DQO mostró resultados similares, 77 de 78 muestras fuera de norma y 74 de 78 al salir de la presa (40 mg/l máx.). El valor máximo encontrado fue de 610,49 mg/l. De acuerdo con el Índice de Calidad del Agua de la Secretaría del Medio Ambiente y Recursos Naturales (SEMARNAT), estos dos parámetros ( $\left.\mathrm{DBO}_{5} \mathrm{y} \mathrm{DQO}\right)$ indican que el agua de este embalse está "fuertemente contaminada".

La calidad del agua de la presa El Ahogado se encuentra fuera de los parámetros aceptables de acuerdo con las instancias del gobierno federal. La presencia de sustancias químicas en este embalse es resultado de la acumulación de todas las aguas residuales del POFA, constituyendo un riesgo sanitario para las poblaciones que se encuentran no solo a orillas del arroyo y la presa El Ahogado, sino también en un radio más amplio.

\section{La presencia de metales pesados en la presa El Ahogado: vaso regulador del Polígono de Fragilidad Ambiental y posibles efectos en la salud}

En un primer momento se revisaron los efectos que producen los metales pesados (bario, cromo, hierro, mercurio y zinc) encontrados en la presa El Ahogado y los riesgos sanitarios a los que están expuestos los habitantes que se encuentran en las inmediaciones de dicho afluente. Se recurrió a la Agencia para Sustancias Tóxicas y el Registro de Enfermedades ${ }^{58}$. De aquí en adelante, las descripciones se sustentan en dicha agencia.

\footnotetext{
58. https://www.atsdr.cdc.gov/es/toxfaqs/es_tfacts22.html
}

El bario es un metal blanco-plateado que existe en el ambiente solo en minerales que contienen mezclas de elementos. Se combina con otras sustancias químicas, por ejemplo, azufre, carbono y oxígeno, para formar compuestos de bario. Se usa para la fabricación de pinturas, ladrillos, cerámicas, vidrio y caucho. Además, es utilizado por las industrias de gas y petróleo. La exposición a este metal puede causar perturbaciones gastrointestinales y debilidad muscular. La ingesta de bario en proporción más elevada a las que ocurren normalmente en los alimentos y el agua puede producir vómitos, calambres estomacales, diarrea, dificultad para respirar, aumento o disminución de la presión sanguínea, adormecimiento de la cara y debilidad muscular.

Las muestras realizadas por la CEA en torno a la presencia de cromo en el agua no sobrepasaban los límites permitidos por la Ley Federal de Derechos, Disposiciones Aplicables en Materia de Aguas Nacionales, 2015. Sin embargo, en nuestros recorridos exploratorios nos hemos percatado de la presencia de varias empresas cromadoras a orillas del arroyo El Ahogado. El cromo se encuentra en forma natural en rocas, animales, plantas y el suelo. El cromo es un metal (0) que se utiliza en la industria acerera. El cromo (VI) y (III) se utilizan en cromado, colorantes y pigmentos, curtido de cuero y preservación de madera. Asimismo, el cromo (III) es un elemento nutritivo de los humanos que contribuye a usar los azúcares, las proteínas y las grasas. La exposición al cromo (VI) puede provocar irritación del revestimiento interno de la nariz, úlceras nasales, secreción nasal y problemas respiratorios tales como asma, tos, falta de aliento o respiración jadeada. El efecto en animales que ingieren compuestos de cromo (VI) son anemia e irritación y úlceras en el estómago y en el intestino delgado. En el campo observamos ganado vacuno pastando por la presa El Ahogado. El Departamento de Salud y Servicios Humanos (DHHS), la Agencia Internacional para la Investigación del Cáncer (IARC) y la Agencia de Protección al Ambiente de los E.U.A. han determinado que los compuestos de cromo (VI) son carcinogénicos en seres humanos. Para los trabajadores, la inhalación de cromo (VI) puede producir cáncer de pulmón y en el agua potable puede provocar tumores estomacales.

El hierro es el cuarto elemento más abundante en la corteza terrestre (5\%). Es un metal maleable, tenaz, de color gris plateado y magnético. Este elemento se encuentra en la carne, productos integrales, papas y vegetales. El cuerpo humano lo absorbe de animales más rápido que de las plantas. Es una parte esencial de la hemoglobina: el agente colorante rojo de la sangre que 
transporta el oxígeno a través de nuestros cuerpos. La inhalación excesiva de óxido de hierro puede provocar cáncer de pulmón ${ }^{59}$.

El mercurio es un metal que se encuentra en el ambiente y tiene varias formas químicas. Es un líquido inodoro, de color blanco-plateado brillante. Al calentarlo se transforma en un gas inodoro e incoloro. Este elemento se utiliza en la producción de gas de cloro y sosa cáustica y también se requiere en termómetros, tapaduras dentales y pilas. El sistema nervioso es muy sensible a todas las formas de mercurio. La exposición a altos niveles de mercurio metálico, inorgánico u orgánico puede causar un daño permanente en los riñones, el cerebro y al feto. La exposición por corto tiempo a altos niveles de vapores de mercurio metálico puede causar lesiones al pulmón, náusea, vómitos, diarrea, aumento de la presión sanguínea o del pulso, sarpullidos e irritación a los ojos. Algunos de estos síntomas son padecidos por pobladores de El Salto y Juanacatlán ${ }^{60}$.

Por último, revisaremos el caso del zinc. Es un elemento que se presenta comúnmente en la corteza terrestre. Se encuentra en el aire, suelo y agua. Se utiliza para evitar el óxido, en baterías de celdas secas y mezclado con otros metales para fabricar aleaciones como el bronce. Inhalar grandes cantidades de zinc puede producir una enfermedad llamada fiebre de vapores de metal, que es generalmente curable. Sin embargo, poco se sabe de los efectos a largo plazo de respirar polvos o vapores de zinc.

La exposición a estos metales pesados, presentes en los cuerpos de agua, pueden afectar a los sistemas nervioso, gastrointestinal y respiratorio de las personas. Como podemos darnos cuenta, la presencia de estos metales en la presa El Ahogado es producto, en su mayoría, de la actividad industrial que se suscita en el POFA, como lo señalan algunos de los estudios revisados. Dicha labor requiere de estos elementos para la elaboración de productos metal-mecánicos, electrónicos, farmacéuticos y alimenticios.

\section{La actividad industrial en el Polígono de Fragilidad Ambiental: una caracterización de la degradación ambiental}

En este apartado conoceremos la distribución de la actividad manufacturera establecida al sur de la

\footnotetext{
59. https://www.lenntech.es/periodica/elementos/fe.htm

60. http://www.udg.mx/es/noticia/encuentran-metales-pesados-y-bacterias-en-aire-y-suelo-de-el-salto-y-juanacatlan
}

ZMG en el POFA. Para ello, se seleccionaron algunas de las actividades manufactureras con base en el Directorio Estadístico Nacional de Unidades Económicas (DENUE). Entre las actividades elegidas se encontraron las siguientes: alimenticia (1.262), metal-mecánica (1.037), plástica (196), química (160), transporte (64), papelera (62), electrónica (36) y textil (31) (Mapa 8).

La mayoría de las empresas manufactureras se encuentran asentadas en periférico sur (en la parte superior del área investigada) entre los límites municipales de Zapopan, Tlaquepaque y Guadalajara. De igual forma, las hallamos hacia el sur de la ZMG, en los municipios de Tlajomulco de Zúñiga, El Salto, Tonalá y Juanacatlán. En suma, existen 2.848 empresas; 2.301 en micro (0 a 10 personas), 366 en pequeña (11 a 50 personas), 124 en mediana (51 a 250 personas) y 57 en grande (250 y más $)^{61}$. Dicha concentración fabril y urbana ha generado una degradación ambiental presente en los escurrimientos de la cuenca El Ahogado que forma parte del POFA. De esta forma, "se hace todo por buscar y explotar nuevas fuentes de abasto, sin contemplar estrategias para cuidar, sanear y reusar el agua"62 (Mapa 9).

Con base en el Mapa 9 podemos darnos una idea de lo que representa la actividad manufacturera (color gris) y los asentamientos humanos (puntos rojos y azules) en el sistema de una cuenca hidrológica. Las aguas residuales (triángulos) provenientes de estos sectores son conducidas a través de las corrientes superficiales aguas arriba (desde el bosque La Primavera y todo periférico sur) hacia la parte baja de la misma (presa El Ahogado). En ese contexto, podemos encontrar una diversidad de empresas asentadas en dicho territorio, predominando las industrias alimenticias y metal-mecánicas (Gráfico 2).

La actividad manufacturera en el POFA representa el $24 \%$ de la producción manufacturera de la ZMG y el $14 \%$ de lo que se genera en el estado de Jalisco. Sin lugar a dudas, la industria asentada en este territorio forma parte del funcionamiento de la economía local, nacional e internacional. De la misma manera, es parte de la degradación ambiental. Estas actividades productivas y los asentamientos urbanos se han desplegado en el acuífero de Toluquilla. El mismo se encuentra sujeto a la disposición de tres decretos de veda: 1951, 1976 y

\footnotetext{
61. Estas unidades económicas son las que reconoce el Instituto Nacional de Estadística y Geografía. Consultar en https://www.inegi.org.mx/contenidos/programas/ce/2009/doc/minimonografias/m_pymes.pdf

62. Lezama Escalante, 2018, 81.
} 
Mapa 8. Empresas manufactureras en el POFA

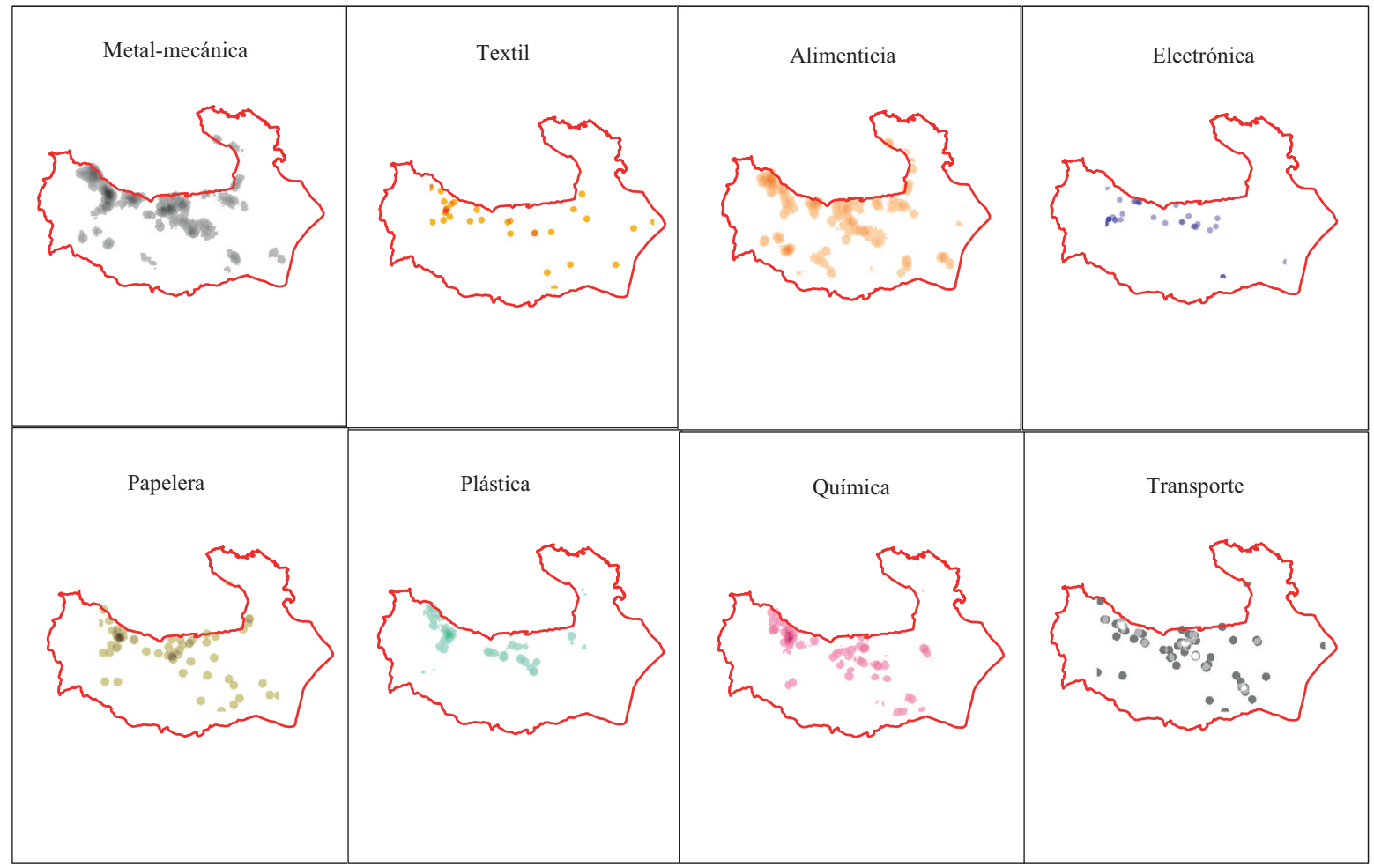

Fuente: elaboración propia con base en la página web del DENUE https://www.inegi.org.mx/app/mapa/denue/

Mapa 9. Corrientes superficiales, descargas residuales, industria y asentamientos humanos, 2018
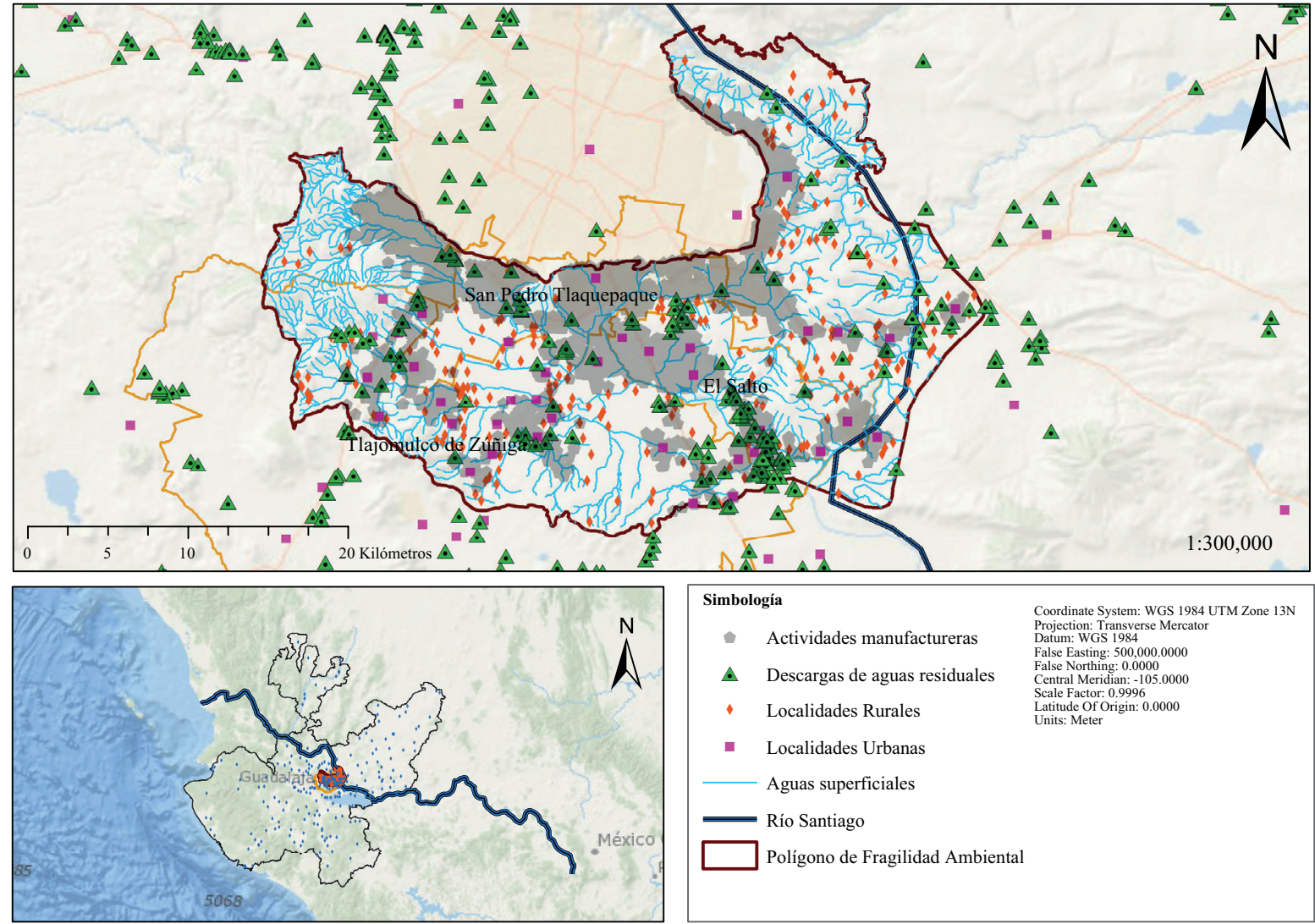

Fuente: elaboración propia con base en https://www.gob.mx/semarnat/acciones-y-programas/registro-de-emisiones-y-transf erencia-de-contaminantes-retc 
Gráfico 2. Industria manufacturera en Jalisco, ZMG y POFA, 2010

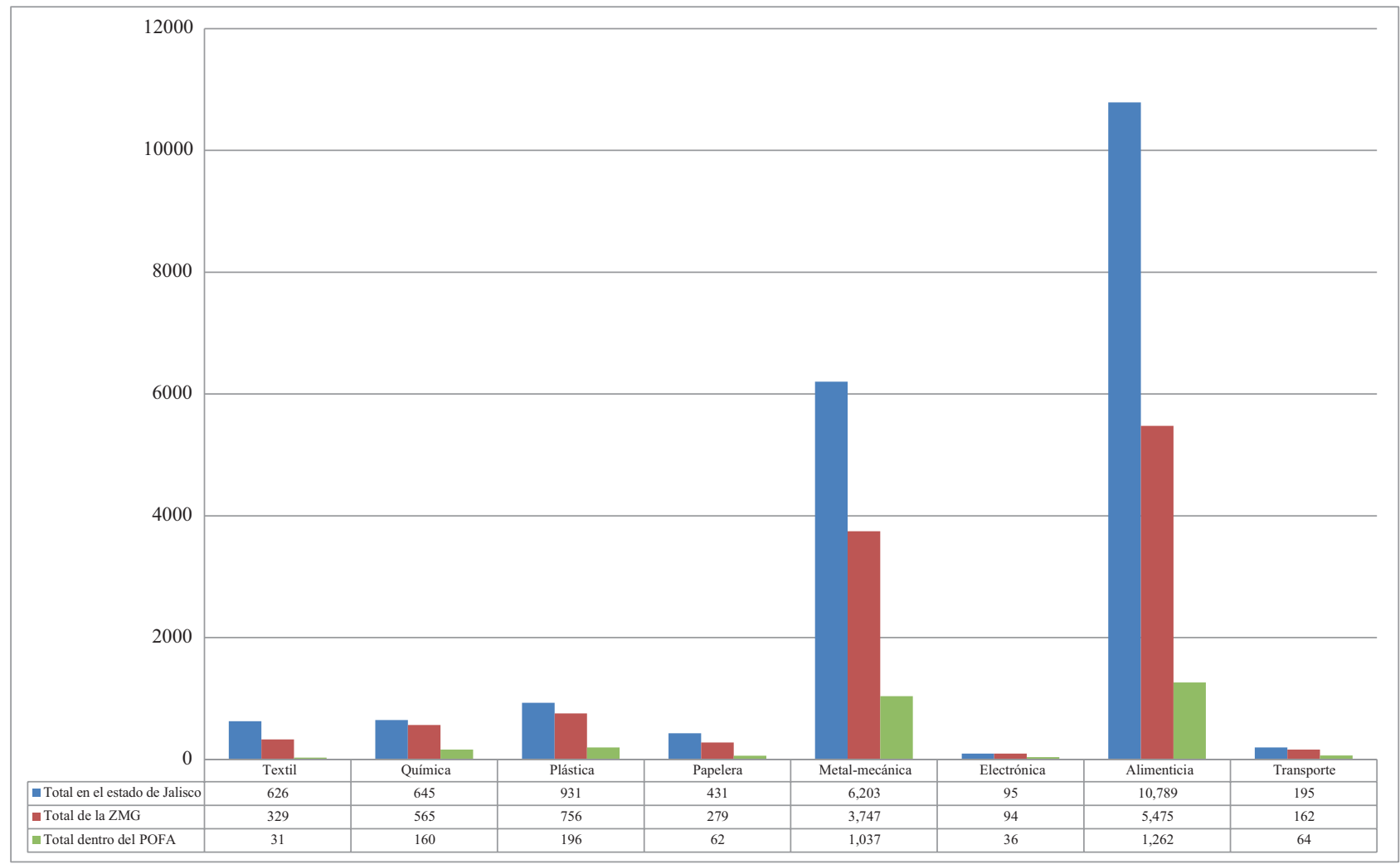

Fuente: elaboración propia, con base en DENUE, 2018.

1984. En el primero de ellos se expresaba lo siguiente: "[...] se establece veda por tiempo indefinido para la construcción o ampliación de obras de alumbramiento de aguas del subsuelo en los Valles de Atemajac, Tesistán y Toluquilla, Jal." ${ }^{63}$ (Mapa 10).

En el Mapa 10 podemos observar que el acuífero cuenta con una extensión de $632 \mathrm{~km}^{2}$, lo que representa el 84,80 \% de la superficie total del POFA (línea roja). En un sentido estricto y bajo las condiciones en las que se encuentra el acuífero, no se debería permitir la construcción de viviendas en estos límites ${ }^{64}$. En el caso de El Salto, donde se concentra la mayor parte de las empresas manufactureras (grandes) y su superficie total está en la zona de veda, la industria es la mayor beneficiaria. Este sector tiene 51 concesiones ante la CONAGUA, seguido de los servicios: 26 , agrícola: 12 , público y diferentes usos con 9 cada uno, doméstico: 2 y pecuario con $1^{65}$. La industria -como se señala en

\footnotetext{
63. CONAGUA, 2015, 5.

64. En primera instancia porque en los pozos que abastecen a la población se han detectado "concentraciones superiores a las establecidas como límites máximos permisibles por la Norma Oficial Mexicana NOM-127SSA1-1994 para el agua destinada al consumo humano de los siguientes elementos: Fe, Mn, Hg, Mg y As" (CONAGUA, 2015, 8). Asimismo, en 1995 se habían detectado casos de fluorosis entre los habitantes.

65. Consultado en http://sina.conagua.gob.mx/sina/tema.php?tema=usos Agua.
}

el párrafo anterior - tiene un número de concesiones mayor que el resto de los sectores. En algunos fraccionamientos de El Salto ${ }^{66}$ y Tlajomulco de Zúñiga, los pobladores han tenido que salir a las calles para exigir el abastecimiento regular del servicio de agua potable. Esto nos habla de una desigualdad social en el reparto del recurso, violando así el Derecho Humano Universal al Agua (Figura 1).

En la Figura 1 observamos a los pobladores de tres colonias: Lomas del Verde Ejidal, Lomas de San Juan y Jardines del Verde, pertenecientes al municipio de El Salto, Jalisco. Ellos son producto de ese crecimiento metropolitano, desordenado, y de los incumplimientos de la autoridad municipal en la dotación de los servicios públicos. Llevaban casi once años sin servicio de agua potable (el municipio los abastecía por medio de camiones cisterna, pero era insuficiente). Y así como ellos, la escasez de agua la padecen los habitantes de nuevos fraccionamientos ${ }^{67}$ en otras partes del POFA.

\footnotetext{
66. Cerca de veinte personas del fraccionamiento La Azucena bloquearon la carretera a El Salto con el propósito de que se le dotara del servicio de agua potable ya que tenían varios días sin el servicio. El occidental, 2007 https://www.eloccidental.com.mx/local/desesperados-habitantes-de-el-salto-por-la-falta-de-agua-1295308.html

67. En los últimos quince años me ha tocado presenciar estas manifestaciones en los fraccionamientos de Parques del Castillo, La Azucena, Villas de la Alameda y los tres casos mencionados en el texto.
} 
Mapa 10. Veda en el acuífero de Toluquilla en el POFA, 2010
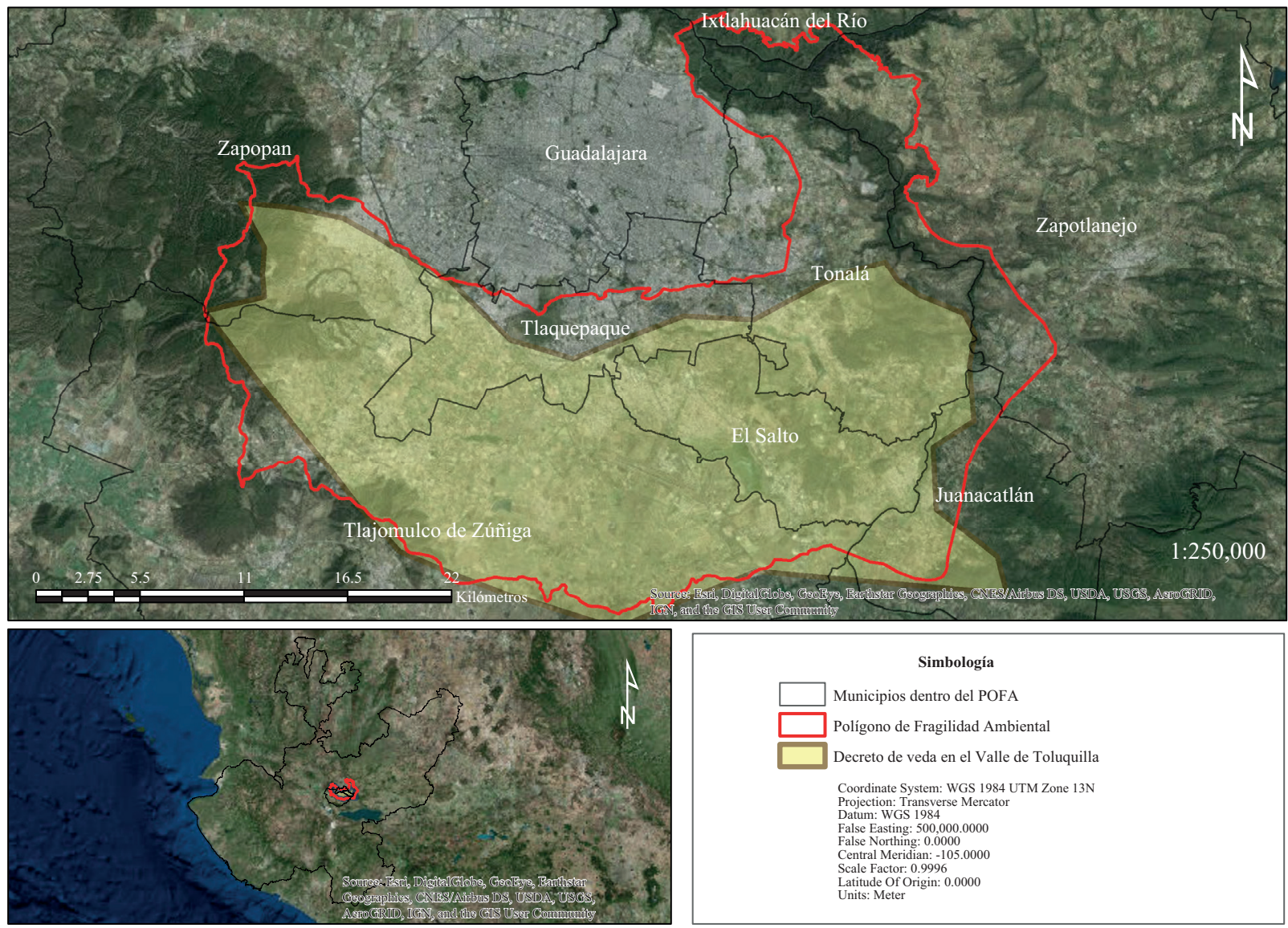

Fuente: elaboración propia con base en CONAGUA, 2010 y SEMADET, 2018.

Figura 1. Pobladores del municipio de El Salto, Jalisco, México

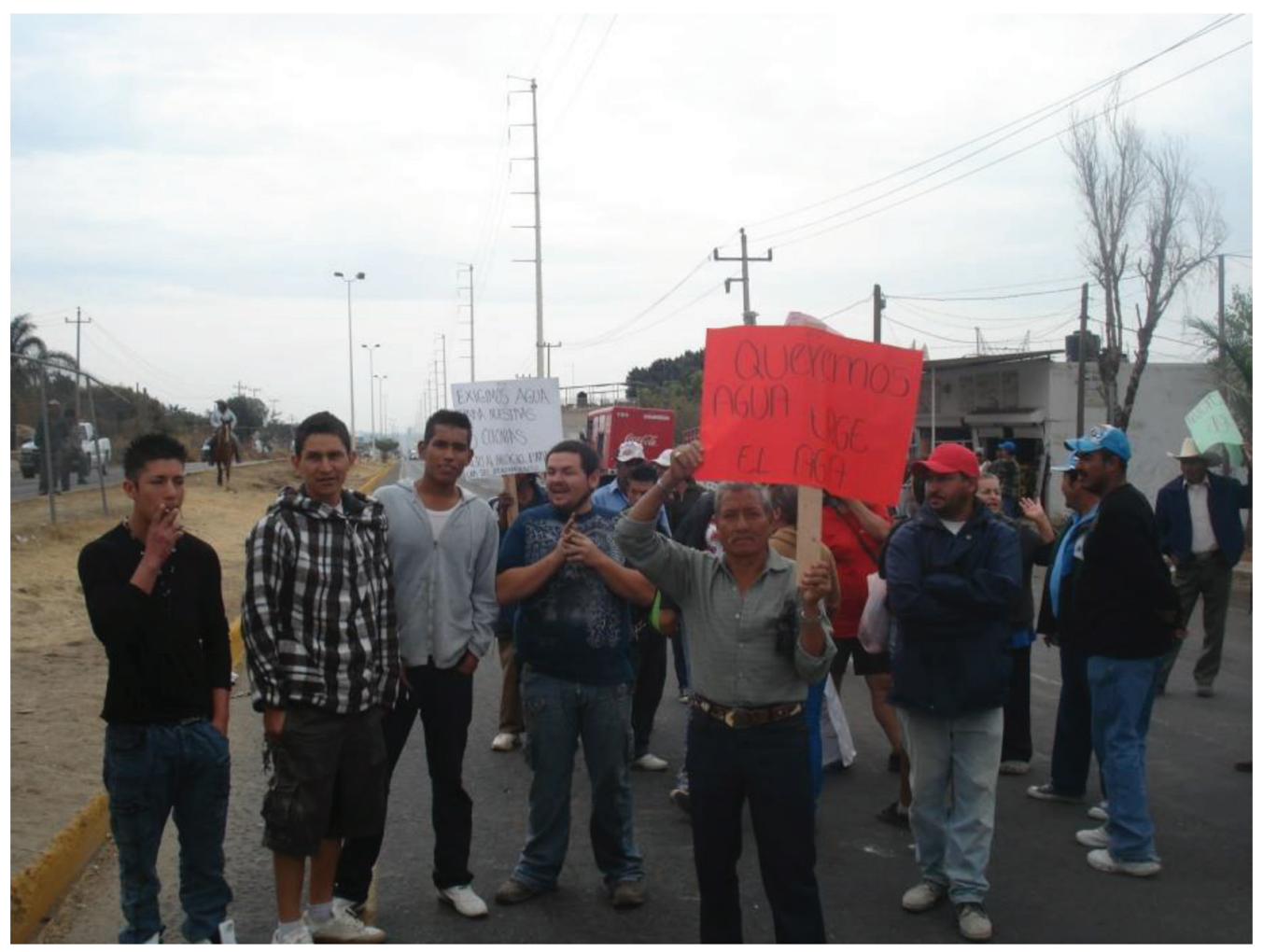

Fuente: Enrique Castillo Figueroa. 


\section{Aportaciones}

Con base en los trabajos analizados, referentes a la calidad del agua superficial, se realizó una proyección socioambiental. En consecuencia, 149.955 habitantes localizados a una distancia de $5 \mathrm{~km}$ del arroyo El Ahogado (por ambos lados del afluente) estarían expuestos a los riesgos sanitarios, distribuidos en parte de los municipios de Guadalajara, Tlajomulco de Zúñiga, Tlaquepaque, Juanacatlán y El Salto. Estas aguas se unen con el río Santiago y, de acuerdo con nuestro cálculo, 407.781 habitantes más se encontrarían expuestos a los mismos padecimientos. En este sentido, se sumarían los pobladores de los municipios de Zapotlanejo, Tonalá e Ixtlahuacán del Río. Junto a los mencionados con anterioridad hablamos de un total de 557.736 personas expuestas a la presencia de metales pesados en el agua superficial.

Los problemas de salud que se pueden presentar en la población del resto del POFA, en relación con las sustancias peligrosas encontradas en el agua superficial, son los siguientes: molestias gastrointestinales, debilidad muscular, irritación en vías respiratorias, úlceras nasales, secreción nasal y problemas respiratorios (tos, falta de aliento o respiración). Otros de los efectos son el daño permanente en los riñones, el cerebro, náuseas, vómitos, diarrea, aumento de la presión sanguínea o del pulso, sarpullidos e irritación en los ojos, así como cáncer de pulmón y daños a los fetos.

Estamos frente a la re-victimización del espacio socioambiental, es decir, la industria se asentó en un sistema hídrico que había sido utilizado por la actividad agrícola a inicios del siglo XX. No obstante, y como se corroboró en los mapas, existen aún 11 presas que captan el agua para la actividad agropecuaria. La cuestión es, ¿qué calidad de agua reciben, si en el mismo espacio existen 2.848 empresas manufactureras y no existe un registro de las que tienen o no PTAR?

\section{Conclusiones}

La expansión de la ciudad de Guadalajara y su zona metropolitana se ha dado de una forma desordenada hacia el sur de esta, donde la industria se asentó desde hace 40 años. Esto ha generado una serie de problemáticas urbanas y ha puesto en evidencia el deterioro ambiental. Los gobiernos municipales y la autoridad que se les confiere en el artículo 115 de la Constitución Política de los Estados Unidos Mexicanos, han otorgado a la iniciativa privada permisos para la construcción de viviendas de interés social ${ }^{68}$. En este caso, ejemplificamos lo acontecido en el municipio de Tlajomulco de Zúñiga, que creció a una tasa del 12,92 (mayor al resto de los municipios metropolitanos). En el año 2006 se construyeron en esta localidad 53.798 viviendas. Esto significa que, a partir de este año, se sumarían 236.711 habitantes al territorio (con base al promedio de 4,4 habitantes por vivienda, de acuerdo con el censo de población y vivienda, 2000). En el POFA viven 1.411 .099 habitantes, que representan el 32 \% de la población total de la ZMG. Las acciones realizadas por las autoridades del estado de Jalisco no han sido suficientes para reducir la contaminación del agua superficial. Así lo demuestran los trabajos aquí analizados.

La propia autoridad estatal y federal ha documentado el deterioro ambiental de esta parte del estado de Jalisco desde la década de 1980. Con base en nuestros cálculos realizados y representados gráficamente, 2.848 empresas manufactureras (pequeñas, medianas y grandes) se encuentran instaladas en el POFA. Estas representan el $24 \%$ de la producción en la ZMG y el $14 \%$ del total de la entidad jalisciense. Existe una correspondencia entre la presencia industrial y la de los metales pesados en la parte baja del POFA ${ }^{69}$. Tres de los trabajos analizados ${ }^{70}$ encontraron en el agua superficial: arsénico, cadmio, cromo, mercurio, plomo y níquel. Se ha demostrado que la presencia de los contaminantes no solo se encuentra en los cuerpos de agua (río Santiago, arroyo y presa El Ahogado), sino que está presente también en los organismos de la población infantil (en algunas localidades dentro de este espacio geográfico $)^{71}$.

El Estado propició el cambio de uso de suelo con la promesa de desarrollar económicamente la región. A lo largo de 40 años ha documentado la degradación ambiental y no fue sino hasta el año 2010 cuando reconoció la gravedad de la contaminación del agua superficial tras las exigencias de la población organizada en los municipios de El Salto y Juanacatlán. No obstante, las medidas adoptadas no han sido suficientes para reducir el impacto ambiental en esta zona. Por lo tanto, y como se reconoció en los trabajos analizados, continúa la presencia de metales pesados y

\footnotetext{
68. Para personas trabajadoras con crédito otorgado por el Estado a pagar entre 30 y 35 años.

69. Arellano Aguilar, Ortega Elorza y Gesundheit Montero, 2013

70. Comisión Estatal del Agua y Ayma, 2006. Comisión Estatal del Agua, 2017. Arellano Aguilar, Ortega Elorza y Gesundheit Montero, 2012 y 2013.

71. Universidad Autónoma de San Luis Potosí y Comisión Estatal del Agua, 2010.
} 
otras sustancias peligrosas en el arroyo y la presa El Ahogado.

Los gobiernos municipales y las empresas inmobiliarias condenan a nuevos pobladores, quienes no investigan los riesgos ambientales, la cobertura de servicios urbanos y adquieren viviendas dentro del POFA. En este espacio se ha decretado una veda en la perforación y extracción de aguas subterráneas. Lo que nos parece incongruente es que se permita al mismo tiempo el crecimiento poblacional hacia esta zona. En algunas localidades de El Salto (La Azucena, Lomas del Verde Ejidal y Parques del Castillo), los pobladores han cerrado vialidades para exigir el abastecimiento de agua. Eso nos parece desigual, ya que la industria no ha parado sus actividades por falta del líquido.

En este trabajo se pudo comprobar que la contaminación del agua superficial no se genera solo al sur de la ZMG, sino que involucra a otros estados de la República Mexicana (Guanajuato, Estado de México, Michoacán, Jalisco y Nayarit). Este último recibe las aguas residuales que se producen en los Estados mencionados antes de desembocar en el Océano Pacifico, lo cual nos habla de una degradación ambiental que inicia en lo local, para impactar en lo global.

Han pasado 40 años del primer indicio de degradación ambiental, registrado por una dependencia del gobierno federal, y no se ha reconocido aún la relación existente entre las enfermedades de los pobladores y la contaminación del agua a pesar de sus propios estudios limnológicos y epidemiológicos en los que se ha demostrado que los metales pesados y otras sustancias se encuentran en el organismo de los niños. Es un espacio etiquetado y revictimizado en que la industria no carece de agua y contamina. Por otra parte, los habitantes quedan expuestos a la degradación ambiental y a los riesgos sanitarios.

\section{Bibliografía}

Aledo, A. 2006: "Desigualdad y grandes obras públicas: la ampliación del Canal de Panamá", Portularia, VI (2), 59-87. http://rabida.uhu.es/dspace/bitstream/handle/10272/526/ b1520088.pdf

Arellano-Aguilar, O., Ortega Elorza, L. y Gesundheit Montero, P. 2012: Estudio de la contaminación en la cuenca del río Santiago y la salud pública en la región. México, Agrupación un Salto de Vida A.C., Greenpeace, Unión de Científicos comprometidos con la Sociedad. https://agua.org.mx/wp-content/ uploads/2016/04/Estudio-de-la-contaminacion-en-la-cuencadel-rio-santiago-y-la-salud-publica-en-el-region.pdf
Arellano Aguilar, O., Ortega Elorza, L. y Gesundheit Montero, P. 2013: "Distribución espacial de las fuentes de contaminación fija en el alto Santiago" en Peniche, S., Romero, M., Cortés, J. H., González, F., Guzmán, M., Macías, E. y Zavala, G.: Gobernanza del agua en las ciudades. México, Universidad de Guadalajara, 155-170.

AYMA Ingeniería y Consultoría, 2003: Estudio de monitoreo y modelación de la calidad del agua de los ríos Santiago y Verde del estado de Jalisco. México, Comisión Estatal de Agua y Saneamiento (CEAS) Jalisco.

Beck, U. 1986: La sociedad del riesgo. Hacia una nueva modernidad. Barcelona (España), Paidós Ibérica.

Castillo, E. 2019: Construcción social del espacio en torno a la fragilidad ambiental al sur de la Zona Metropolitana de Guadalajara: el caso de las poblaciones La Huizachera, El Salto y Villas de la Alameda, Tlajomulco de Zúníga, tesis de doctorado, Universidad de Guadalajara, Guadalajara (México).

Comisión Estatal del Agua. 2017: Sistema de Calidad de Agua. CEA. http://info.ceajalisco.gob.mx/sca/

Comisión Estatal del Agua y AyMA Ingeniería y Consultaría, S.A. de C.V. 2006: Identificación y caracterización de fuentes de contaminación de la cuenca directa del río Santiago, entre los municipios de Ocotlán y Tonalá, y directa del río Zula. http:/l info.ceajalisco.gob.mx/transparencia/pdf/ops/rio_santiago/ presentacion_ejecutiva.pdf

CONAGUA, 2010: Decreto que declara de interés público la conservación de los mantos acuíferos de la zona circunvecina a la veda de los Valles de Atemajac, Tesistán y Toluquilla, Jal. http://dof.gob.mx/nota_detalle.php?codigo=4843828\&fecha $=07 / 04 / 1976$

CONAGUA, 2015: Actualización de la disponibilidad media anual de agua en el acuífero Toluquilla (1402), Estado de Jalisco. Publicada en el Diario Oficial de la Federación el 20 de abril de 2015.

Consejo Estatal de Ciencia y Tecnología del Estado de Jalisco. 2012: Diagnóstico Integral del Polígono de Fragilidad Ambiental (POFA) y su entorno 2012. Centro de Investigación y Asistencia en Tecnología y Diseño del Estado de Jalisco.

Cousido, M. A. 2010: "Contaminación de cuencas con residuos industriales: estudio del caso Matanza Riachuelo, Argentina", Revista CENIC. Ciencias Químicas, 41, 1-11. https://www.redalyc. org/pdf/1816/181620500023.pdf

DENUE, 2018: Directorio Estadístico Nacional de Unidades Económicas. Disponible en: https://www.inegi.org.mx/app/mapa/ denue/default.aspx

Droste, R. 1997: Theory and practice of water and wastewater treatment. New York (Estados Unidos de América), John Wiley \& Sons Inc.

Durán, J. M., y Torres, A. 2009: "La sustentabilidad de la cuenca del río Santiago y su relación con la metropolización de Guadalajara", Tempo-Revista Cultura, Tecnología y Patrimonio, 4 (7), 1-10. 
González, E. 1987: El Salto. Industria y urbanización de Guadalajara, tesis de licenciatura, Universidad de Guadalajara, Guadalajara (México).

Greenpeace, 2016: Alto a la catástrofe ecológica del río Santiago. Reporte técnico. https://www.business-humanrights.org/sites/default/files/documents/Reporte\%20Alto\%20a\%20la\%20 \%20Cat \%C3\%A1 strofe\%20Ecol\%C3\%B3gica\%20de\%20R\%C3\%ADo\%20Santiago.pdf

Instituto Mexicano de Tecnología del Agua (IMTA), 2011: Actualización del estudio de calidad del agua del río Santiago (desde su nacimiento en el lago de Chapala, hasta la presa Santa Rosa). México, CEA Jalisco/Instituto Mexicano de Tecnología del Agua. https://docplayer.es/31366200-Actualizacion-del-estudio-de-calidad-del-agua-del-rio-santiago-desde-su-nacimiento-en-el-lagode-chapala-hasta-la-presa-santa-rosa-contenido.html

Instituto Nacional de Estadística y Geografía (INEGI), 2000: XII Censo General de Población y Vivienda. Consultado en https:// www.inegi.org.mx/programas/ccpv/2000/

Instituto Nacional de Estadística y Geografía (INEGI). 2010: Censo de Población y Vivienda. Consultado en https://www. inegi.org.mx/programas/ccpv/2010/

Leff, E. 2014: La apuesta por la vida. Imaginación sociológica e imaginarios sociales en los territorios ambientales del sur. México, Vozes editora.

Lezama Escalante, C. 2018: "Los costes sociales del proyecto de la presa El Zapotillo: el caso de Temacapulín", Agua y Territorio, 12, 71-82. https://doi.org/10.17561/at.12.4070

Marques Harres, M. 2018: "Águas poluídas: uma história da poluição hídrica na Bacia Hidrográfica do Rio dos Sinos, RS", Agua y Territorio, 11, 70-82. https://doi.org/10.17561/at.11.2439

McCulligh, C., Páez, J. C. y Moya, G. 2007: Mártires del Río Santiago. Guadalajara (México), Instituto Mexicano para el Desarrollo Comunitario, A. C. IMDEC, A. C., Instituto de Valores Integrales y Desarrollo Ambiental, (VIDA) A. C. http://hdl. handle.net/11117/5338

McCulligh, C., Tetreault, D. y Martínez, P. 2012: "Conflicto y contaminación: El movimiento socio-ecológico en torno al río Santiago", en Ochoa García, H. y Bürkner, H. J. (Coords.): Gobernanza y gestión del agua en el occidente de México: la metrópoli de Guadalajara. Guadalajara (México), ITESO, 129172. http://hdl.handle.net/11117/451
Meira Cartea, P. A. 2006: "Elogio de la educación ambiental", Trayectorias, VIII (20-21), 41-51. http://trayectorias.uanl. $\mathrm{mx} / 20 \mathrm{y} 21 /$ dossier/elogio.pdf

Ochoa García, H. 2012: "Gestión del agua en la periferia urbana: Tlajomulco de Zúñiga", en Ochoa García, H. y Bürkner, H. J. (Coords.): Gobernanza y gestión del agua en el occidente de México: la metrópoli de Guadalajara. Guadalajara (México), ITESO, 245-282. http://hdl.handle.net/11117/451

OMS. 2020: "Enfermedades y riesgos asociados a las deficiencias en los servicios de agua y saneamiento". https://www. who.int/water_sanitation_health/diseases-risks/es/

Rojas-Ramírez, J. J. P. 2018: "Modelo analítico sobre los conflictos intergubernamentales por el agua en la cuenca Lerma, México", Agua y Territorio, 12, 95-104. https://doi. org/10.17561/at.12.4072

Secretaría de Agricultura y Recursos Hidráulicos, Subsecretaría de Planeación (SARH). 1980: Características de Calidad de Agua de la Presa El Ahogado en el Estado de Jalisco. Guadalajara, Centro de Estudios Limnológicos. https://www. inecc.gob.mx/repositorio/ae/ae_003128.pdf

SEMADET, 2018: Polígono de Fragilidad Ambiental (POFA). Consultado en http://sigat.semadet.jalisco.gob.mx/mxsig/

Torres-Rodríguez, A. 2018: "Las metrópolis y sus periferias: cinturones de marginación, pobreza y desechos urbanos en la ZMG", Agua y Territorio, 12, 25-38. https://doi.org/10.17561/ at. 12.4066

Universidad Autónoma de San Luis Potosí y Comisión Estatal del Agua Jalisco. 2010: Propuesta metodológica para la implantación de una batería de indicadores de salud que favorezcan el establecimiento de programas de diagnóstico, intervención y vigilancia epidemiológica en las poblaciones ubicadas en la zona de influencia del proyecto de la presa Arcediano en el estado de Jalisco. Guadalajara (México), CEA. https://transparencia.info.jalisco.gob.mx/sites/default/files/INFORME\%20 FINAL\%20ARCEDIANO_CEA_UEAS_JALISC0_2011_1\%20 -\%20copia_opt.pdf

Verkasalo, P. K., Kokki, E., Pukkala, E., Vartiainen, T., Kiviranta, H., Penttinen, A. \& Pekkanen, J. 2004: "Cancer Risk Near a Polluted River in Finland", Environmental Health Perspectives, 112 (9), 1026-1031. https://doi.org/10.1289/ehp.6741 